\title{
Flora das cangas da Serra dos Carajás, Pará, Brasil: Lejeuneaceae
}

Flora of the canga of the Serra dos Carajás, Pará, Brazil: Lejeuneaceae

Anna Luiza Ilkiu-Borges ${ }^{1,3}$ \& Fúvio Rubens Oliveira-da-Silva ${ }^{2}$

\begin{abstract}
Resumo
Este é um tratamento taxonômico com descrição, ilustração e comentários morfológicos para as espécies de Lejeuneaceae das áreas de canga na Serra dos Carajás, estado do Pará. Foram identificados 12 gêneros e 22 espécies, sendo Lejeunea oligoclada é um novo registro para a região Norte do Brasil e Lejeunea angusta e Schiffneriolejeunea amazonica novos registros para o estado do Pará.
\end{abstract}

Palavras-chave: FLONA Carajás, brioflora, hepáticas, taxonomia.

\begin{abstract}
This is a taxonomic treatment with descriptions, illustrations and morphological comments for the Lejeuneaceae from areas of canga in the Serra dos Carajás, Pará state. Twelve genera and 22 species were identified, of which Lejeunea oligoclada is a new record for the northern region of Brazil, and Lejeunea angusta and Schiffneriolejeunea amazonica are newly recorded for the state of Pará.
\end{abstract}

Key words: FLONA Carajás, bryoflora, liverworts, taxonomy.

\section{Lejeuneaceae}

Lejeuneaceae Cavers é a maior família dentre as hepáticas folhosas, com 71 gêneros e mais de 1900 espécies distribuídas no globo (Söderström et al. 2016). No Brasil ocorrem 57 gêneros e 285 espécies (Gradstein \& Costa 2003; Costa \& Peralta 2015). É caracterizada pelos ramos predominantemente do tipo-Lejeunea, presença de um único arquegônio por ginoécio, filí́dios íncubos com um lobo dorsal e uma pequeno lóbulo ventral ligado ao lobo por uma quilha, e presença de anfigastros (ausentes apenas em Cololejeunea) com rizóides na base (Gradstein 1994; Gradstein et al. 2001; Gradstein \& Ilkiu-Borges 2009). Na Serra dos Carajás foram registrados 12 gêneros e 22 espécies em áreas de canga.

\section{Chave de identificação dos gêneros de Lejeuneaceae das áreas de canga da Serra dos Carajás}

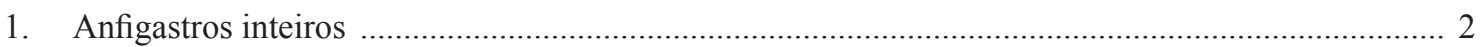

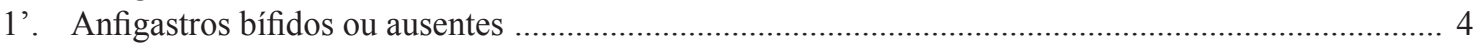

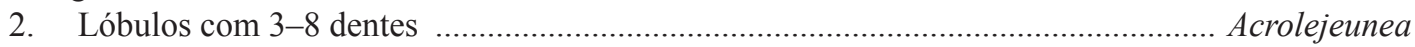

2'. Lóbulos com 1-2 dentes ................................................................................................ 3

3. Merófito ventral com até 4 células de largura. Células do lobo isodiamétricas, trigônios triangulares a radiados. Brácteas femininas arredondadas, última bracteola da série inteira

Lopholejeunea

3'. Merófito ventral com 4-8 células de largura. Células do lobo elongadas, trigônios cordados. Brácteas femininas com ápice agudo, última bracteola da série bífida .. Schiffneriolejeunea

4. Anfigastros ausentes Cololejeunea

4'. Anfigastros presentes 5

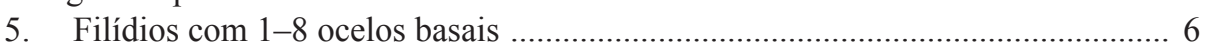

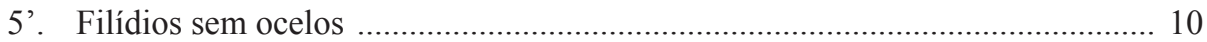

\footnotetext{
'Museu Paraense Emílio Goeldi, Av. Magalhães Barata 376, São Braz, 66040-170, Belém, PA, Brasil.

${ }^{2}$ Universidade Federal Rural da Amazônia/Museu Paraense Emílio Goeldi, Prog. Pós-graduação em Ciências Biológicas - Botânica Tropical, Av. Perimetral 1901, 66530-070, Belém, PA, Brasil.

${ }^{3}$ Autor para correspondência: ilkiu-borges@museu-goeldi.br
} 
6. Lóbulo cobrindo $2 / 3$ do comprimento do lobo ou mais (filídios com 1 ocelo basal de difícil visualização) Microlejeunea

6'. Lóbulo cobrindo $1 / 2$ do comprimento do lobo ou menos ................................................................. 7

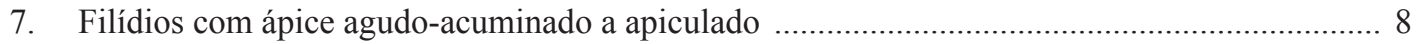

7'. Filídios com ápice arredondado a agudo (nunca acuminado ou apiculado) .............................. 9

8. Anfigastros com lobos agudos e filiformes ............................................. Drepanolejeunea

8'. Anfigastros com lobos arredondados ......................................................... Harpalejeunea

9. Paredes celulares alaranjadas. Margens dos filídios inteiras ou com dentes próximos ao ápice. Periantos geralmente com 4 cornos ou 4 quilhas baixas. Utrículos presentes ou ausentes Ceratolejeunea

9'. Paredes celulares hialinas. Margens dos filídios inteiras a fracamente crenuladas. Periantos com 5 quilhas. Utrículos ausentes Pycnolejeunea

10. Lóbulo com 1 ou 2 dentes (paralelos) no ápice, papila hialina distal (dificilmente visível) Cheilolejeunea 10'. Lóbulo com 1 no ápice, papila hialina proximal (facilmente visível) ............... 11

11. Lobulos cobrindo $2 / 3$ do comprimento do lobo ou mais. Lóbulos com lobos filiformes (até 3 células de comprimento). Margem dos filídios inteiras Microlejeunea

11'. Lobulos cobrindo ca. $1 / 2$ do comprimento do lobo ou menos. Lóbulos com lobos agudos (nunca filiformes). Margem dos filídios inteiras a denticuladas

12. Margens dos filídios inteiras. Ápice dos filídios arredondados a obtuso Lejeunea

12'. Margens dos filídios denticuladas por células projetadas. Ápice dos filídios sub-agudos a agudo-acuminados Prionolejeunea

\section{Acrolejeunea (Spruce) Schiffn.}

Gênero pantropical representado por 21 espécies, das quais duas ocorrem no Brasil (Costa \& Peralta 2015; Wang et al. 2014; Söderström et al. 2016). Crescem principalmente sobre casca de árvores, raramente sobre rochas, podem ser encontradas em ambientes de pastagens, savanas, vegetação de cerrado, mata ciliar e no dossel de florestas tropicais, pois habitam preferencialmente lugares secos e com alta exposição solar (Gradstein 1994; Gradstein et al. 2001). O gênero é reconhecido pela disposição dos filídios fortemente imbricados, dentes pequenos ao longo da margem do lóbulo, trigônios cordados, presença de filídios caducos e periantos com muitas quilhas (6-10) (Gradstein 1994; Gradstein et al 2001).

\section{Chave de identificação das espécies de Acrolejeunea das áreas de canga da Serra dos Carajás}

1 Lóbulo com 3-4 dentes

1'. Lóbulo com 5-8 dentes

1.1. Acrolejeunea emergens (Mitt.) Steph., Pflanzenw. Ost-Afrikas C: 65, 1895. Phragmicoma emergens Mitt., Philos. Trans. 168: 397, 1879.

Fig. 1a-c

Plantas marrom-escuras, $0,9-1,8 \mathrm{~mm}$ de largura. Merófito ventral com 4-6 células de largura. Filídios fortemente imbricados, convolutos quando secos, estendidos a \pm esquarroso quando úmidos, ovalado-suborbiculares, $650-1100 \times 550-850$ $\mu \mathrm{m}$, concavos, ápice redondo, margem inteira.
1.1. Acrolejeunea emergens 1.2. Acrolejeunea torulosa
Células isodiamétricas a fracamente alongadas, 20-35 × 15-25 $\mu \mathrm{m}$, trigônios cordados. Lóbulos ovalado-orbiculares a ovalado-subretangular, 1/2-2/5 o comprimento do lobo, com 2-4 dentes eretos a fracamente incurvados, dentes com 1-2 células de altura. Anfigastros inteiros, amplamente obovados, 3-4,5× a largura do caulídio. Perianto não observado. Material selecionado: Parauapebas, Serra Norte, N1, $6^{\circ} 00 ' 30,8^{\prime}$ 'S, 50 $0^{\circ} 17^{\prime} 55,1^{\prime \prime} \mathrm{W}, 679$ m, 31.VIII.2015, A.L. Ilkiu-Borges et al. 3629 (MG). 
Acrolejeunea emergens difere de A. torulosa, principalmente pelo número de dentes na margem do lóbulo, visto que $A$. emergens apresenta de 3-4 dentes, enquanto $A$. torulosa possui de 5-8. Segundo Gradstein \& Costa (2003), no Brasil essa espécie ocorre sobre casca de árvores em vegetação secundária, restingas e em áreas cultivadas. $\mathrm{Na}$ Serra dos Carajás, essa espécie ocorreu em canga aberta sobre tronco de árvore viva.

América tropical, África e Índia. No Brasil: AC, AM, BA, CE, DF, ES, GO, MA, MG, MS, MT, PA, RJ, RO, RR e SP. Serra dos Carajás: Serra Norte: N1.

1.2. Acrolejeunea torulosa (Lehm. \& Lindenb.) Schiffn., Hepat. (Engl.-Prantl): 128, 1893.

Jungermannia torulosa Lehm. \& Lindenb., Nov. Stirp. Pug. 6: 41, $1834 . \quad$ Fig. 1d-e

Plantas verdes a marrons, $0,8-1,8 \mathrm{~mm}$ de largura. Merófito ventral com 4 células de largura. Filídios densamente imbricados, convolutos quando secos, estendidos a \pm esquarrosos quando úmidos, ovalado-orbiculares, 700-1200× 700-1000 $\mu \mathrm{m}$, côncavos, ápice redondo a subobtuso, margem inteira. Células isodiamétricas a fracamente alongadas, $20-35 \times 15-26 \mu \mathrm{m}$, trigônios cordados. Lóbulos ovalado-triangulares, 1/2-2/5 o comprimento do lobo, com 5-8 dentes curtos, eretos a fracamente incurvados. Anfigastros inteiros, amplamente obovados, 3-4× a largura do caulídio. Perianto obovado, imerso, com 6-10 quilhas.

Material selecionado: Canaã dos Carajás, Serra Sul, S11A, 06 20 '56,9"S, 50²6'58,1"W, 714 m, 10.V.2017; F.R. Oliveira-da-Silva et al. 34 (MG); S11C, 6²1'19,1'S, 50²3'27,4”'W, 29.IV.2015, A.L. IlkiuBorges et al. 3518 (MG). Parauapebas, Serra Norte, N1, 601'32,3”'S, 50 17'32,5”'W, 719 m, 28.IV.2015, A.L. Ilkiu-Borges et al. 3438 (MG); N2, 603'19,5”'S, 50¹5'14,6”'W, 685 m, 28.IV.2015, A.L. Ilkiu-Borges et al. 3432 (MG); N4, 604'18”'S, 50¹1'39,2”'W, 617 m, 30.IX.2015, A.L. Ilkiu-Borges et al. 3710 (MG); N5, 603'19,6”'S, 50¹5'15,4”'W, 685 m, 28.IV.2015, A.L. Ilkiu-Borges et al. 3422 (MG); N6, 66'42"S, $50^{\circ} 11$ '01,9' W, $711 \mathrm{~m}, 24 . \mathrm{II} .2016$, A.L. Ilkiu-Borges et al. 3759 (MG); N7, 69'27,2”'S, 50¹0'15,2”'W, 695 $\mathrm{m}, 24 . I I .2016$, A.L. Ilkiu-Borges et al. 3785 (MG); N8, 6¹0'00,6”S, 5009'34,1”'W, 716 m, 29.IV.2015, A.L. Ilkiu-Borges et al. 3804 (MG).

Em campo, esta espécie pode ser reconhecida pela disposição dos filí́dios fortemente imbricados e, sob microscópio, é identificada principalmente pelo lóbulo com 5-8 dentes. Segundo Gradstein (1994) e Gradstein \& Costa (2003), A. torulosa é a espécie mais comum do gênero no Neotrópico e ocorre em locais secos e abertos, sobre troncos vivos e raramente sobre rochas. Nas cangas da Serra dos Carajás, essa espécie ocorre principalmente em canga aberta, onde há muita exposição solar, sobre tronco de árvores vivas e troncos em decomposição.

América do Sul tropical. No Brasil: AC, AM, AL, BA, DF, ES, GO, MA, MG, MS, MT, PA, PE, PR, RJ, RO, RR, RS e SP. Serra dos Carajás: Serra Norte: N1, N2, N4, N5, N6, N7 e N8; Serra Sul: S11A e S11C.

2. Ceratolejeunea (Spruce) J.B.Jack \& Steph.

Gênero pantropical com 40 espécies, sendo que 14 ocorrem no Brasil (Söderström et al. 2016; Costa \& Peralta 2015). Os membros deste grupo ocorrem em terras baixas aos páramos, em habitat secos ou úmidos, predominantemente em troncos vivos, mas ocasionalmente sobre folhas, rochas, substratos artificiais e raramente sobre solo (Dauphin 2003). Este gênero é caracterizado pela cor amarronzada das plantas, com paredes celulares pigmentadas de alaranjadas a marrom pálido, ocelos nos filídios, presença de utrículos e perianto geralmente com 4 cornos ou projeções bulbosas (Dauphin 2003; Gradstein et al. 2001).

\section{Chave de identificação das espécies de Ceratolejeunea das áreas de canga da Serra dos Carajás}

1. Filídios com margem inteira e ápice incurvado. Perianto com 4 quilhas baixas, infladas (sem cornos) Ceratolejeunea guianensis

1'. Filídios com margem inteira a dentenada e ápice \pm plano a \pm incurvado. Perianto com 4 cornos (com ou sem projeções laminares)

2. Anfigastros mais largos que longos. Perianto com 4 cornos cilíndricos afunilados Ceratolejeunea cornuta

2'. Anfigastros mais longos que largos. Perianto com 4 cornos pequenos, com 1 projeção \pm laminar, às vezes bifurcadas Ceratolejeunea cubensis 


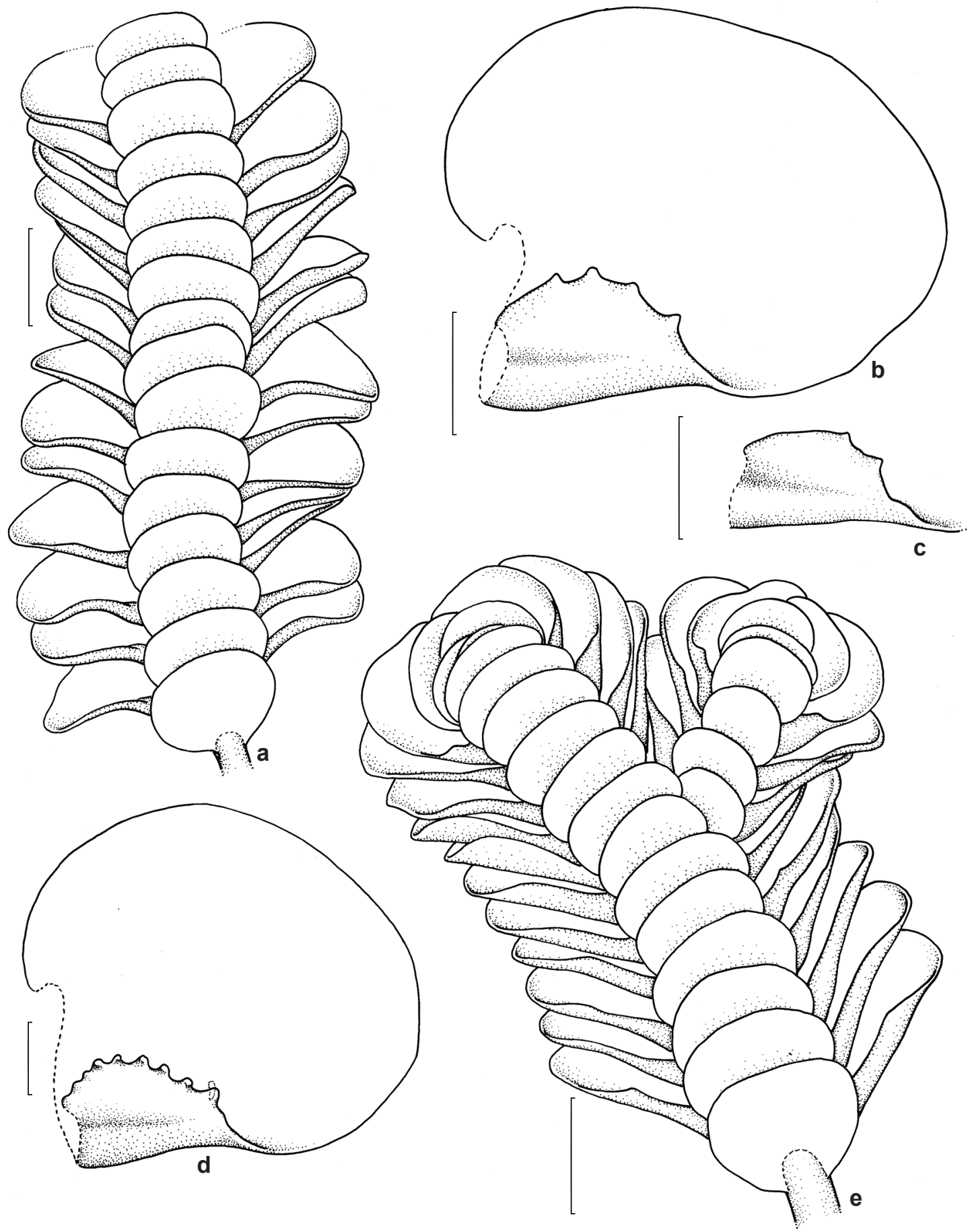

Figura 1 - a-c. Acrolejeunea emergens - a. hábito; b. filídio em vista ventral; c. lóbulo. d-e. Acrolejeunea torulosa d. filídio em vista ventral; e. hábito. Barras: a, $\mathrm{e}=500 \mu \mathrm{m}$; b, $\mathrm{c}=250 \mu \mathrm{m}, \mathrm{d}=200 \mu \mathrm{m}$. (a; b. baseado em Gradstein \& Ilkiu-Borges 2009).

Figure 1 - a-c. Acrolejeunea emergens - a. habit; b. leaf in ventral view; c. lobule. d-e. Acrolejeunea torulosa - d. leaf in ventral view; e. habit. Bars: a, e $=500 \mu \mathrm{m} ; \mathrm{b}, \mathrm{c}=250 \mu \mathrm{m}, \mathrm{d}=200 \mu \mathrm{m}$. (a; b. after Gradstein \& Ilkiu-Borges 2009). 
2.1. Ceratolejeunea cornuta (Lindenb.) Steph., Pflanzenw. Ost-Afrikas C: 65, 1895.

Jungermannia cornuta Lindenb., Nova Acta Phys.-Med. Acad. Caes. Leop.-Carol. Nat. Cur. 14(suppl.): 23, 1829.

Fig. 2a-b

Plantas verde-amarronzadas a marrons, $0,5-1,5 \mathrm{~mm}$ de largura. Merófito ventral com 2 células de largura. Filídios imbricados, ovalados, $600-800 \times 370-600 \mu \mathrm{m}$, ápice redondo a amplamente agudo, \pm plano a \pm incurvado, margem inteira a denteada próximo ao ápice. Células medianas isodiamétricas, 20-25 $\mu \mathrm{m}$, ocelos 1-2 basais isolados. Lóbulos ovalados, 1/5-1/7 do comprimento do lobo, frequentemente esféricos, às vezes reduzidos, dente apical curto ou longo, falcado, papila hialina proximal. Anfigastros bífidos, ovalado-orbiculares a reniformes, geralmente mais largos que longos, $2-5 \times$ a largura do caulídio, base arredondada a cordada, lobos agudos, margem inteira, plana. Perianto obovado, com 4 cornos cilíndricos afunilados.

Material selecionado: Canaã dos Carajás, Serra Sul, S11C, 6²2'57,9'S, 50²3'07'W, 29.IV.2015, A.L. Ilkiu-Borges et al. 3476 (MG). Parauapebas, Serra Norte, N2, 603'19,4”S, 50 15'17,7'W, 685 m, 31.VIII.2015, A.L. Ilkiu-Borges et al. 3618 (MG); N3, 06 $02^{\prime} 36,1^{\prime \prime} \mathrm{S}$, $50^{\circ} 12^{\prime} 30^{\prime \prime}$ W, 13.V.2017; F.R. Oliveira-da-Silva et al. 172 (MG); N4, 604'18”'S, 50¹1'39,2”'W, 617 m, 3.IX.2015, A.L. Ilkiu-Borges et al. 3702 (MG); N5, 602'36,4'S, $50^{\circ} 05^{\prime} 25,1$ '”, 604 m, 2.IX.2015, A.L. Ilkiu-Borges et al. $3696(\mathrm{MG})$.

A principal característica desta espécie são os anfigastros ovalado-orbiculares a reniformes, periantos com 4 cornos cilíndricos e afunilados, lóbulos pequenos (1/5-1/7 do comprimento do lobo) e frequentemente esféricos e 1-2 ocelos basais, geralmente isolados. Ceratolejeunea cornuta ocorre sobre troncos de árvores vivas e ocasionalmente sobre rochas e folhas (Gradstein \& Costa 2003; Dauphin 2003). Nas cangas da Serra dos Carajás, essa espécie ocorreu somente sobre tronco vivo, em mata baixa sobre canga, perto de brejos e em canga aberta.

Neotropical. No Brasil: AC, AM, AP, BA, CE, PA, PR, RJ, RO, RR, SC e SP. Serra dos Carajás: Serra Norte: N2, N3, N4 e N5; Serra Sul: S11C.

2.2. Ceratolejeunea cubensis (Mont.) Schiffn., Hepat. (Engl.-Prantl): 125, 1893.

Lejeunea cubensis Mont., Hist. Phys. Cuba, Bot., Pl. Cell.: 481, 1842.

Fig. 2c-f

Plantas verde-amarronzadas, $0,5-1,5 \mathrm{~mm}$ de largura. Merófito ventral com 2 células de largura.
Filídios imbricados, ovalados, 500-700 × 350-550 $\mu \mathrm{m}$, ápice redondo a amplamente agudo, \pm plano a \pm incurvado, margem inteira a denteada próximo ao ápice. Células medianas isodiamétricas, $20-25 \mu \mathrm{m}$, ocelos geralmente 2 lado a lado ou geminados, às vezes formando um grupo de até 8 ocelos (próximo a ramos férteis). Lóbulos ovalados, 1/3-1/5 do comprimento do lobo, raramente reduzidos, dente apical curto, falcado, papila hialina proximal. Anfigastros bífidos, ovalados, geralmente mais longos que largos, $(2-) 3 \times$ a largura do caulídio, base arredondada, lobos agudos, margem \pm inteira, plana. Perianto obovado, com 4 cornos pequenos, com 1 projeção \pm laminar, às vezes bifurcadas.

Material selecionado: Canaã dos Carajás, Serra Sul, S11B, 621'19,1'S, 50²3'27,4”'W, 29.IV.2015, A.L. Ilkiu-Borges et al. 3525 (MG).

De acordo com Dauphin (2003), essa espécie apresenta uma grande variação principalmente no ápice do filídio (com ou sem dentes), no desenvolvimento e forma do perianto, número e disposição dos ocelos e quanto ao tamanho dos anfigastros, o que faz com que seja confundida com outras espécies de Ceratolejeunea. Dauphin (2003) descreve o perianto de C. cubensis, obcônicos com 4 cornos delgados ou inflados.

O único espécime de C. cubensis coletado na Serra dos Carajás apresentou características típicas como os anfigastros mais longos que largos, os ocelos lado a lado ou geminados. Entretanto, o perianto apresentou 4 cornos pequenos, com 1 projeção \pm laminar, às vezes bifurcadas, o que não é típico de $C$. cubensis. Projeções laminares similares foram observadas em C. maranhensis Silva Brito \& Ilk.-Borg. (Brito \& Ilkiu-Borges 2012), entretanto nessa espécie o perianto, além dos cornos apicalmente ornamentados e subdivididos em 2-3 cílios ou lacínias, apresenta a superfície fortemente rugosa por células mamilosas e com paredes celulares uniformemente espessadas.

Essa espécie difere de C. cornuta, que apresenta anfigastros mais largos que longos e perianto com 4 cornos cilíndricos afunilados. Também difere de C. coarina (Gottsche) Schiffn., espécie com a qual C. cubensis pode ser confundida em herbário (Dauphin 2003), por esta apresentar filídios com margem ventral curta e reta e margem dorsal longa e fortemente arqueada, além de perianto com 4 cornos inflados e eretos, como ilustrado por Gradstein \& Ilkiu-Borges (2009).

Essa espécie é muito comum em troncos de árvores vivas e em madeira em decomposição (Gradstein \& Costa 2003). Nas cangas da Serra dos 

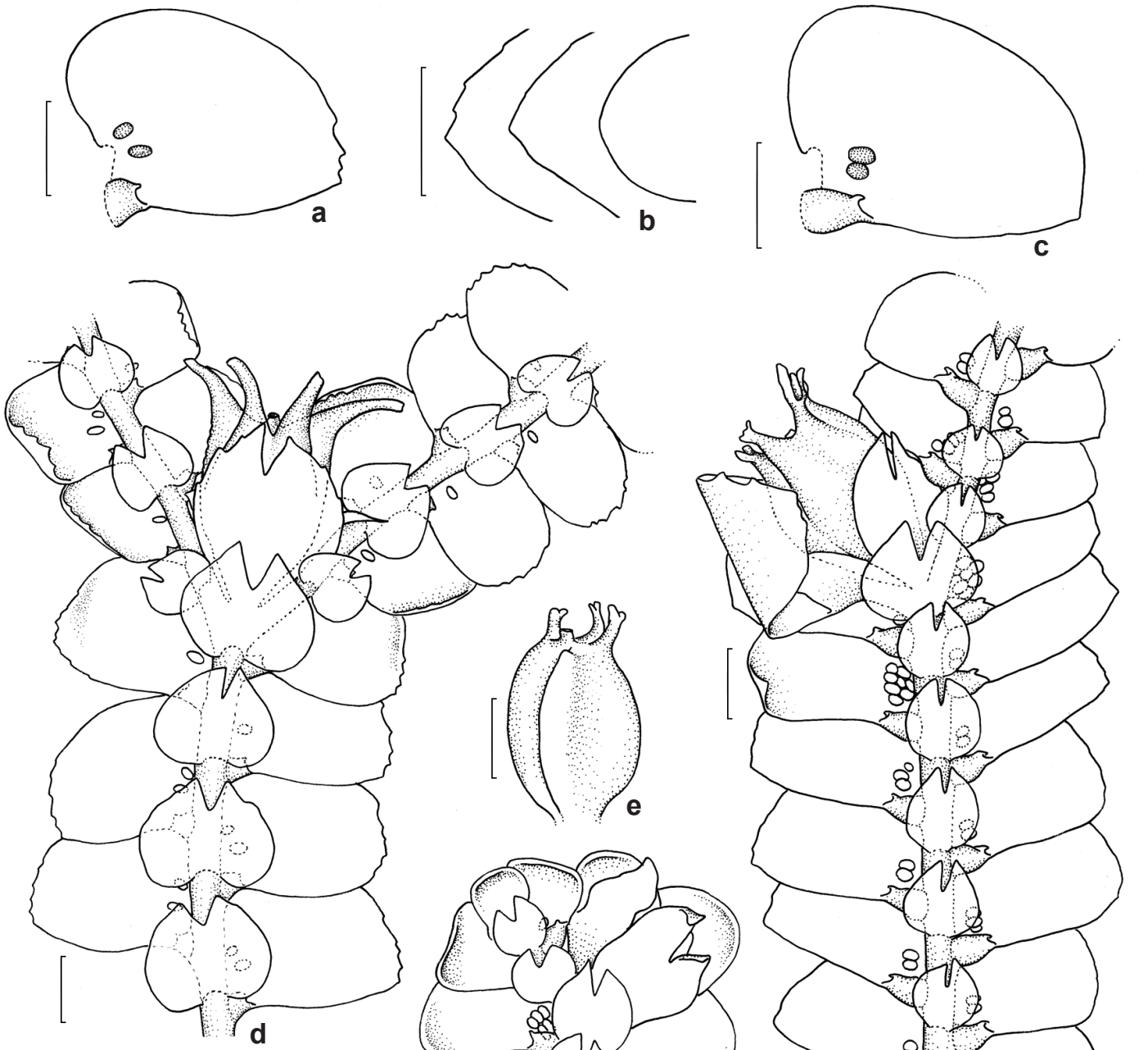
Carajás, ela foi coletada sobre tronco vivo, em mata baixa sobre canga, perto de uma lagoa de macrófitas. América tropical. No Brasil: AC, AL, AM, AP, BA, CE, ES, PA, PB, PE, RJ, RO, SC e SP. Serra dos Carajás: Serra Sul: S11B.

2.3. Ceratolejeunea guianensis (Nees \& Mont.) Steph., Sp. Hepat. (Stephani) 5: 416, 1913.

Lejeunea guianensis Nees \& Mont., Ann. Sci. Nat. Bot. (sér. 2) 14: 335, 1840.

Fig. 2g-i

Plantas verde-amarronzadas, 0,5-1,2 mm de largura. Merófito ventral com 2 células de largura. Filídios imbricados, ovalados, 400-700 × 350-550 $\mu \mathrm{m}$, ápice redondo, incurvado, margem inteira. Células medianas isodiamétricas, $15-20 \mu \mathrm{m}$, ocelos 1-6 contíguos, raro isolados. Lóbulos ovalados, 1/3-1/4 do comprimento do lobo, raramente reduzidos, dente apical curto, falcado, papila hialina proximal. Anfigastros bífidos, ovaladoorbiculares, geralmente tão longos quanto largos, $(2-) 3 \times$ a largura do caulídio, base arredondada, lobos agudos, margem inteira, plana. Perianto obovado, com 4 quilhas pequenas, infladas.

Material selecionado: Canaã dos Carajás, Serra Sul, S11C, 6²2'57,9'S, 50²3'07'W, 29.IV.2015, A.L. IlkiuBorges et al. 3478 (MG); Serra do Tarzan, 6¹9'45'S, $50^{\circ} 00 ' 27,4$ 'W, 757 m, 1.IX.2015, A.L. Ilkiu-Borges et al. 3667 (MG). Parauapebas, Serra Norte, N2, 603'19,4”'S, $50^{\circ} 15^{\prime} 17,7^{\prime \prime} \mathrm{W}, 685$ m, 31.VIII.2015, A.L. Ilkiu-Borges et al. 3610 (MG); N5, 606'18,1'S, 5007'49,4”'W, 715 m, 27.IV.2015, A.L. Ilkiu-Borges et al. 3395 (MG).

Ceratolejeunea guianensis também pode se assemelhar a $C$. cubensis, mas as principais diferenças estão no filídio consistentemente inteiro, com ápice incurvado e pela ausência de cornos no perianto. Em C. cubensis, o filídio apresenta margem inteira a denteada na porção distal, com ápice \pm plano a \pm incurvado e perianto com 4 cornos (Dauphin 2003; Gradstein \& Ilkiu-Borges 2009).

Estado Unidos, Brasil, Cuba, Colômbia, Venezuela, Guiana e Guiana Francesa. No Brasil: AM, BA, MA, PA, PE. Serra dos Carajás: Serra Norte: N2 e N5; Serra Sul: S11C e Serra do Tarzan.

\section{Cheilolejeunea (Spruce) Steph.}

O gênero apresenta 170 espécies pantropicais, mas no Brasil ocorrem 46 (Söderström et al. 2016; Bastos 2017). Os membros deste grupo ocorrem sobre casca de árvore, rocha e ocasionalmente em solo (Gradstein et al. 2001). O gênero é reconhecido pela coloração verde pálida, lóbulos com dois dentes, sendo o primeiro dente frequentemente reduzido e o segundo dente desenvolvido, papila hialina distal, células foliares com corpos de óleo grosseiramente granulares (raramente finamente granulares), inovação pycnolejeunóide ou lejeunóide, perianto inflado com 3-5 quilhas lisas (Ye et al. 2015; Bastos 2016).

\section{Chave de identificação das espécies de Cheilolejeunea das áreas de canga da Serra dos Carajás}

1. Filídios com ápice agudo a curto-acuminado ......................................... Cheilolejeunea acutangula

1'. Filídios com ápice arredondado, raramente amplamente agudo ....................................................... 2

2. Anfigastros 4-6 $\times$ a largura do caulídio ................................................ Cheilolejeunea trifaria

2'. Anfigastros 1,5-3 $\times$ a largura do caulídio .......................................................................... 3

3. Filídios amplamente estendidos, planos, com margem ventral \pm reta, ápice arredondado. Quilha do lóbulo inteira. Filídios caducos presentes .................................. Cheilolejeunea adnata

3'. Filídios obliquamente estendidos, \pm concavos, com margem ventral curvada, ápice arredondado a amplamente agudo (muitos ramos devem ser observados). Quilha do lóbulo \pm inteira a crenulada por papilas lenticulares. Filídios caducos ausentes

Cheilolejeunea oncophylla

3.1. Cheilolejeunea acutangula (Nees) Grolle; j. Hattori Bot. Lab. 45: 173, 1979.

Jungermannia acutangula Nees, Fl. bras. (Martius) 1(1): 357, $1833 . \quad$ Fig. 3a-c

Plantas verde-pálidas, 0,6-1 $\mathrm{mm}$ de largura. Merófito ventral com 2 células de largura. Filídios obliquamente estendidos, subimbricados, ovalados, $350-600 \times 200-400 \mu \mathrm{m}$, ápice agudo a curto acuminado, incurvado, margem \pm inteira a crenulada, margem dorsal e ventral curvadas. Células medianas isodiamétricas, $12-20 \mu \mathrm{m}$, superfície dorsal fracamente papilosa por espessamento das paredes celulares. Lóbulos ovalados, ca.1/4 do comprimento do lobo, quilha crenulada, dente apical longo, falcado, papila hialina distal. Anfigastros bífidos, ovaladoorbiculares, mais largos ou tão longos quanto largos, 2-3 × a largura do caulídio, base cuneada a 


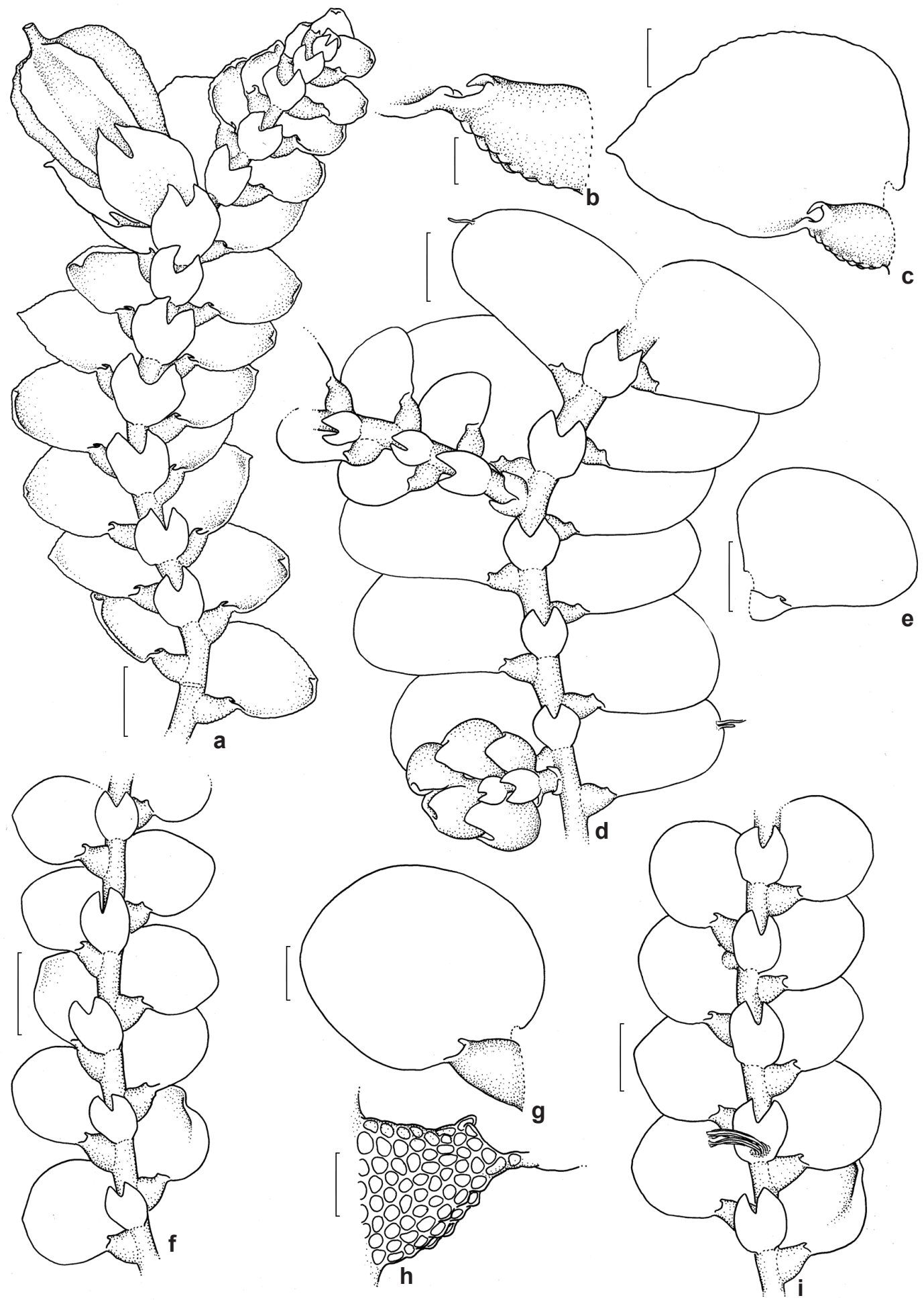

Figura 3 - a-c. Cheilolejeunea acutangula - a. hábito; b. lóbulo; c. filídio em vista ventral. d-e. Cheilolejeunea adnata - d. hábito; e. filídio em vista ventral. f-i. Cheilolejeunea oncophylla - f-i. hábito; g. filídio em vista ventral; h. lóbulo. Barras: a, d, e, f, i= $250 \mu \mathrm{m} ; \mathrm{b}, \mathrm{h}=50 \mu \mathrm{m} ; \mathrm{c}, \mathrm{g}=100 \mu \mathrm{m}$.

Figure 3 -a-c. Cheilolejeunea acutangula - a. habit; b. lobule; c. leaf in ventral view. d-e. Cheilolejeunea adnata - d. habit; e. leaf in ventral view. f-i. Cheilolejeunea oncophylla $-\mathrm{f}-\mathrm{i}$. habit; g. leaf in ventral view; h. lobule. Bars: a, d, e, f, i= $250 \mu \mathrm{m} ; \mathrm{b}, \mathrm{h}=50 \mu \mathrm{m} ; \mathrm{c}, \mathrm{g}=100 \mu \mathrm{m}$. 
arredondada, lobos agudos, margem inteira ou com um dente angular nas laterais, planos. Ginoécio com 1 inovação pycnolejeuneóide, geralmente estéril. Perianto obovado, com 5 quilhas planas. Reprodução vegetativa não observada.

Material selecionado: Canaã dos Carajás, Serra Sul, S11A, 06²0'17,9"S, 50²6'56,8'W, 731 m, 10.V.2017; F.R. Oliveira-da-Silva et al. 172 (MG); Serra do Tarzan, 6¹9'45'S, 5000'27,4”W, 1.IX.2015, A.L. Ilkiu-Borges et al. 3655 (MG). Parauapebas, Serra Norte, N2, 603'19,4'S, 50¹5'17,7'W, 31.VIII.2015, A.L. IlkiuBorges et al. 3612 (MG); N3, 0602'36, '’S, 50¹2'30'W, 693 m, 13.V.2017; F.R. Oliveira-da-Silva et al. 176 (MG); N4, 604'18'S, 50¹1'39,2”W, 3.IX.2015, A.L. Ilkiu-Borges et al. 3704 (MG).

Essa espécie é facilmente distinta das demais espécies de Cheilolejeunea que ocorrem em Carajás, pelos filídios com ápice agudo a curtoacuminado e incurvado, motivo pelo qual pertence ao subgênero Strepsilejeunea. Distingue-se de $C$. oncophylla, que também pertence a esse subgênero, devido ao ápice raramente amplamente agudo desta última espécie e também por apresentar a superfície dorsal dos filídios com espessamentos bem mais visíveis que em $C$. oncophylla, cujas papilas lenticulares são melhor observadas na quilhas de alguns lóbulos.

De acordo com Bastos (2016), essa espécie ocorre em floresta ombrófila, fragmento florestal urbano, restinga, cerrado e campos rupestres, colonizando troncos vivos ou em decomposição. Nas cangas da Serra dos Carajás, a espécie ocorreu frequentemente sobre tronco de árvore viva e raramente sobre tronco em decomposição, em mata baixa sobre canga e canga aberta, próximo a campos brejosos.

Mundo. No Brasil: AL, AM, BA, DF, ES, GO, MG, MT, PA, PE, RJ, RO, RS, SC e SP. Serra dos Carajás: Serra Norte: N2, N3 e N4; Serra Sul: S11A e Serra do Tarzan.

3.2. Cheilolejeunea adnata (Kunze ex Lehm.) Grolle; j. Bryol. 9(4): 529, 1977 [1978].

Jungermannia adnata Kunze ex Lehm., Nov. Stirp. Pug. 6: 46, 1834.

Fig. 3d-e

Plantas verde-pálidas, 0,7-1,5 $\mathrm{mm}$ de largura. Merófito ventral com 2 células de largura. Filídios amplamente estendidos (às vezes subfalcados), contíguos a subimbricados, ovalados, 300-700 × 250-400 $\mu \mathrm{m}$, ápice redondo, plano, margem inteira, às vezes com rizóides marginais (filídios caducos), margem dorsal curvada, ventral reta. Células medianas isodiamétricas, 20-30 $\mu \mathrm{m}$, superfície dorsal lisa. Lóbulos ovalado- triangulares, (1/3-)1/4-1/6 do comprimento do lobo, quilha inteira, dente apical longo, falcado, papila hialina distal. Anfigastros bífidos, suborbiculares, tão longos quanto largos, 1,5-2× a largura do caulídio, base cuneada, lobos agudos, margem inteira, planos. Ginoécio com ou sem 1 inovação pycnolejeuneóide. Perianto obovado, com 2 quilhas laterais e uma quilha ventral larga, inflada. Reprodução vegetativa por filídios caducos.

Material selecionado: Canaã dos Carajás, Serra Sul, S11A, 06²0'56,9'S, 50²6'58, 1'W, 714 m, 10.V.2017; F.R. Oliveira-da-Silva et al. 19 (MG); Serra do Tarzan, 6¹9'45”S, 5000'27,4'W, 785m, 1.IX.2015, A.L. IlkiuBorges et al. 3666 (MG). Parauapebas, Serra Norte, N1, 601'25,5”S, 50¹7'56,3'W, 664 m, 31.VIII.2015, A.L. Ilkiu-Borges et al. 3633 (MG); N2, 603'20,7'S, 50¹5'15,8'W, 688 m, 27.II.2016, A.L. Ilkiu-Borges et al. 3738 (MG); N4, 604'18'S, 50¹1'39,2”W, 617 m, 3.IX.2015, A.L. Ilkiu-Borges et al. 3702 (MG); N5, 606'18,1'S, 5007'49,3'W, 715 m, 27.IV.2015, A.L. Ilkiu-Borges et al. 3380 (MG); N6, 607'41,2”S, 50॰10’34,1”W, 694 m, 3.IX.2015, A.L. Ilkiu-Borges et al. 3738 (MG).

Essa espécie distingue-se das demais espécies em Carajás pelos filídios caducos. Além disso, os filídios amplamente estendidos, quase falcados, planos, geralmente com rizóides marginais, com lóbulos pequenos ovaladotriangulares com dente longo e falcado e anfigastros pequenos (geralmente $1,5 \times$ a largura do caulídio), também são características diagnósticas de Cheilolejeunea adnata.

Esta espécie ocorre em florestas ombrófilas, vegetação de cerrado e restinga, sobre troncos de ávores vivas ou em decomposição, em galhos finos na copa de árvores e raramente sobre folhas (Gradstein \& Costa 2003; Gradstein \& Ilkiu-Borges 2009). Nas cangas da Serra dos Carajás, a espécie ocorreu sobre tronco de árvore viva, rocha de ferro e tronco em decomposição, em mata baixa sobre canga, canga aberta, próximo a entrada de caverna e às margens de lagoa.

América Tropical. No Brasil: AM, BA, MT, PA, PE, PR e SC. Serra dos Carajás: Serra Norte: N1, N2, N4, N5 e N6; Serra Sul: S11A e Serra do Tarzan.

3.3. Cheilolejeunea oncophylla (Ångstr.) Grolle \& M.E.Reiner; j. Bryol. 19(4): 781, 1997.

Lejeunea oncophylla Ångstr., Öfvers. Kongl. Vetensk.-Akad. Förh. 33(7): 86, 1876 [1877].

Fig. $3 f-i$

Plantas verde-pálidas a verde-acastanhadas, 0,5-0,8 $\mathrm{mm}$ de largura. Merófito ventral com 2 células de largura. Filídios obliquamente 
estendidos, distantes a subimbricados, ovaladoorbiculares, 250-500 × 250-400 $\mu \mathrm{m}$, ápice redondo a amplamente agudo (muitos ramos devem ser observados), incurvado, raramente \pm plano, margem inteira, margem dorsal e ventral curvadas. Células medianas isodiamétricas, 15-20 $\mu \mathrm{m}$, superfície dorsal fracamente papilosa por espessamento das paredes celulares. Lóbulos ovalados, 1/3-1/4 do comprimento do lobo, quilha \pm inteira a fracamente crenulada por papilas lenticulares, dente apical curto, curvado, papila hialina distal. Anfigastros bífidos, suborbiculares, geralmente mais longos que largos, 1,5-2 $\times$ a largura do caulídio, base cuneada, lobos agudos, margem inteira, planos. Ginoécio com uma inovação pycnolejeuneóide, geralmente estéril. Perianto obovado, com 5 quilhas planas. Reprodução vegetativa não observada.

Material selecionado: Canaã dos Carajás, Serra Sul, S11B, 6²1'19,1"S, 50²3'27,4"W, 29.IV.2015, A.L. Ilkiu-Borges et al. 3515 (MG); S11C, 6²2'57,9"S, 50²3'07'W, 29.IV.2015, A.L. Ilkiu-Borges et al. 3476 (MG); Serra do Tarzan, 6¹9'45"S, 5000'27,4”W, 758 m, 1.IX.2015, A.L. Ilkiu-Borges et al. 3654 (MG). Parauapebas, Serra Norte, N1, 601'32,3"S, $50^{\circ} 17^{\prime} 32,5^{\prime} \mathrm{W}, 719 \mathrm{~m}, 28 . \mathrm{IV} .2015$, A.L. Ilkiu-Borges et al. 3438 (MG); N2, 603'19,4'S, 50¹5'17,7'W, 685 m, 31.VIII.2015, A.L. Ilkiu-Borges et al. 3611 (MG); N3, 0602'36,1'S, 50¹2'30"W, 693 m, 13.V.2017; F.R. Oliveira-da-Silva et al. 172 (MG); N4, 607'05,5"S, 50¹1'00”W, 715 m, 3.IX.2015, A.L. Ilkiu-Borges et al. 3717 (MG); N5, 606'18'S, $50^{\circ} 07^{\prime} 48,9$ 'W, 715 m, 27.IV.2015, A.L. Ilkiu-Borges et al. 3398 (MG); N6, 607'41,2”S, 50¹0’34,1”W, 694 m, 3.IX.2015, A.L. Ilkiu-Borges et al. 3721 (MG); N7, 69'27,2”S, 50¹0'15,2”W, 695 m, 24.II.2016, A.L. Ilkiu-Borges et al. 3782 (MG).

Cheilolejeunea oncophylla é caracterizada, principalmente, pela superfície dorsal fracamente papilosa do lobo causada pelo espessamento das paredes e isso pode ser bem observado na quilha do lóbulo que frequentemente é crenulada. Papilas lenticulares podem ser observadas. Além disso, essa espécie pertence ao subgênero Strepsilejeunea que tem como característica filídios com ápice agudo e incurvado, característica discreta em $C$. oncophylla (amplamente agudo) e muitos ramos devem ser analisados para observar essa característica (Grolle \& Reiner-Drehwald 1997).

Segundo Grolle \& Reiner-Drehwald (1997), essa espécie ocorre sobre tronco de árvore viva e ocasionalmente sobre rochas. Nas cangas da Serra dos Carajás, ela ocorreu sobre tronco vivo e rochas de ferro, em mata baixa sobre canga, campos brejosos, perto de lagos e córregos temporários de drenagem natural e em canga aberta.

América tropical. No Brasil: AL, AP, BA, GO, MG, PA, PR, RJ, RO, SC e SP. Serra dos Carajás: Serra Norte: N1, N2, N3, N4, N5, N6 e N7; Serra Sul: S11B, S11C e Serra do Tarzan.

3.4. Cheilolejeunea trifaria (Reinw., Blume \& Nees) Mizut.; j. Hattori Bot. Lab. 27: 132, 1964. Jungermannia trifaria Reinw., Blume \& Nees, Nova Acta Phys.-Med. Acad. Caes. Leop.-Carol. Nat. Cur. 12(1): 226, 1824 [1825]. Fig. 4a-b

Plantas verde-pálidas a verde-acastanhadas, 0,7-1,1 mm de largura. Merófito ventral com 2 células de largura. Filídios obliquamente estendidos, imbricados, ovalado-orbiculares, 350-700 × 300-450 $\mu \mathrm{m}$, ápice redondo, plano, margem inteira, margem dorsal e ventral curvadas. Células medianas isodiamétricas, 20-30 $\mu \mathrm{m}$, superfície dorsal lisa. Lóbulos ovalados, 1/4-1/5 do comprimento do lobo, quilha inteira, dente apical curto, falcado, papila hialina distal. Anfigastros bífidos, sub-orbiculares a subreniformes, geralmente mais largos que longos, 3-5× a largura do caulídio, base arredondada a cordada, lobos agudos, margem inteira, planos. Ginoécio com uma inovação pycnolejeuneóide, geralmente estéril. Perianto obovado, com 5 quilhas planas. Reprodução vegetativa não observada.

Material selecionado: Canaã dos Carajás, S11B, 6²1'19,1"S, 50²3'27,4”W, 29.IV.2015, A.L. IlkiuBorges et al. 3518 (MG). Parauapebas, N2, 603'20,1'S, $50^{\circ} 15^{\prime} 14,9$ 'W, 685 m, 28.IV.2015, A.L. Ilkiu-Borges et al. 3429 (MG).

Essa é uma espécie facilmente reconhecida pelas plantas relativamente grandes com filídios obliquamente estendidos, ovalado-orbiculares e anfigastros grandes (3-5 $\times$ a largura do caulídio) sempre mais largos que longos. Esta espécie ocorre sobre rochas, solos e sobre árvores vivas em locais expostos ou sombreados (Gradstein \& Costa 2003). Nas cangas da Serra dos Carajás, essa espécie ocorreu sobre tronco vivo e tronco em decomposição, em mata baixa sobre canga e em canga aberta.

Pantropical. No Brasil: AC, AL, AM, BA, CE, DF, ES, GO, MG, MS, MT, PA, PB, PE, PR, RJ, RR e SP. Serra dos Carajás: Serra Norte: N2; Serra Sul: S11B.

4. Cololejeunea (Spruce) Steph.

É um gênero pantropical com 431 espécies sendo que, no Brasil, ocorrem 37 espécies (Costa \& Peralta 2015; Söderström et al. 2016). Ocorrem 


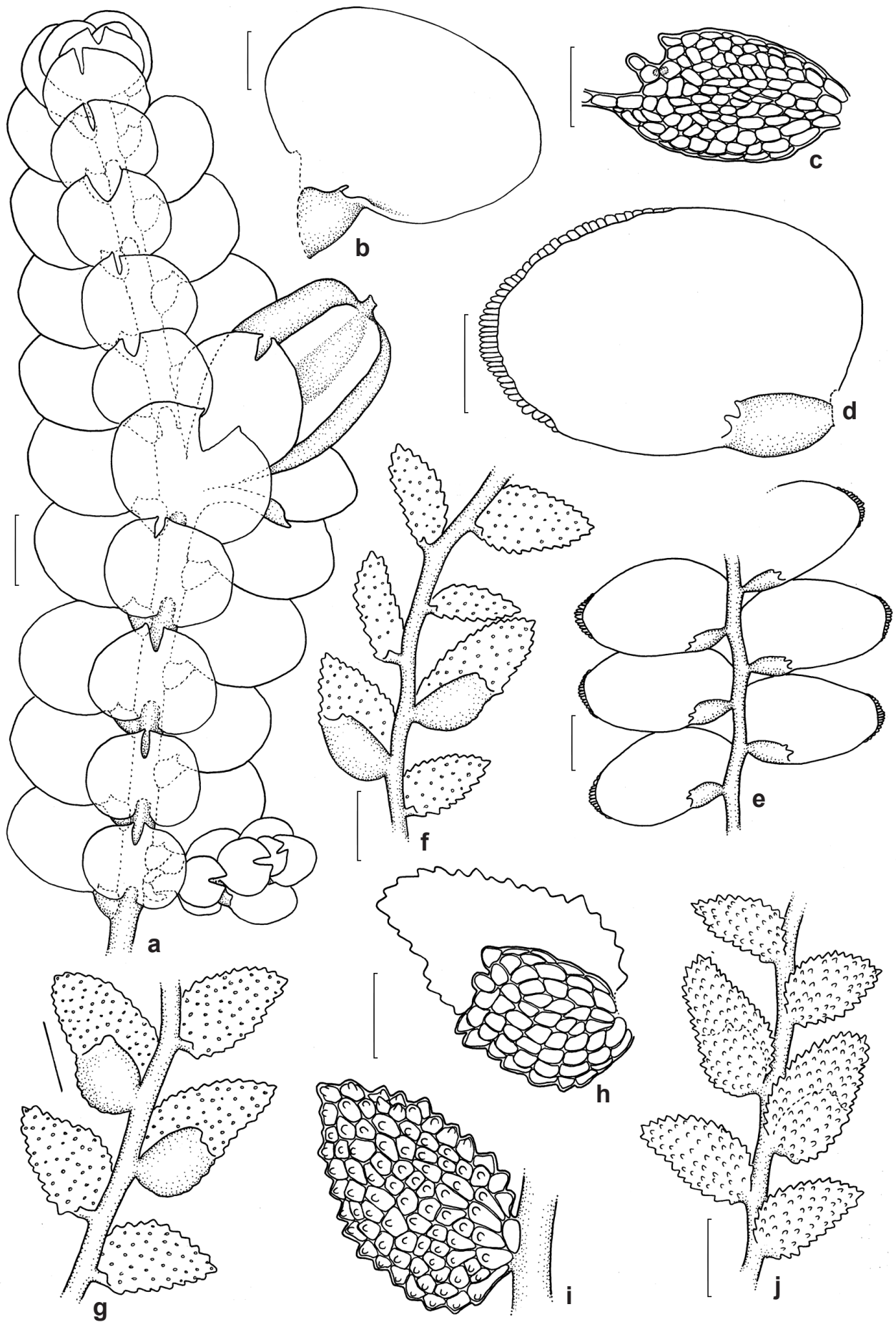

Figura 4 - a-b. Cheilolejeunea trifaria - a. hábito; b. filídio em vista ventral. c-f. Cololejeunea cardiocarpa - c. lóbulo; d. filídio em vista ventral; e. hábito. f-j. Cololejeunea contractiloba - f-g. hábito em vista ventral; h. filídio em vista ventral; i. filí́dio em vista dorsal; j. hábito em vista dorsal. Barras: a, d, e $=250 \mu \mathrm{m} ; \mathrm{b}, \mathrm{c}, \mathrm{f}, \mathrm{g}, \mathrm{j}=100 \mu \mathrm{m}$; $\mathrm{h}, \mathrm{i}=50 \mu \mathrm{m}$. (h, j. baseado em Gradstein \& Ilkiu-Borges 2009 ).

Figure 4 - a-b. Cheilolejeunea trifaria - a. habit; b. leaf in ventral view. c-f. Cololejeunea cardiocarpa - c. lobule; d. leaf in ventral view; e. habit. f-j. Cololejeunea contractiloba - f-g. habit in ventral view; h. leaf in ventral view; i. leaf in dorsal view; j. habit in dorsal view. Bars: a, d, e= $250 \mu \mathrm{m}$; b, c, f, g, j= $100 \mu \mathrm{m} ; \mathrm{h}, \mathrm{i}=50 \mu \mathrm{m}$. (h, j. after Gradstein \& Ilkiu-Borges 2009). 
principalmente sobre folhas, ocasionalmente em troncos vivos, madeira em decomposição e rochas (Pócs et al. 2014). O gênero é reconhecido pela ausência de anfigastros, além de plantas geralmente muito pequenas e delicadas (até $1,8 \mathrm{~mm}$ ), com ramos do tipo-Lejeunea ou -Aphanolejeunea, caulídio muito fino com geralmente 1-2 células de medula em espécies neotropicais, merófito ventral de 1-2 células (raramente maior) e filídios com ou sem lóbulos (geralmente reduzidos no subgênero Aphanolejeunea), margem inteira, denticulada ou com uma borda hialina (Gradstein \& Costa 2003; Gradstein \& Ilkiu-Borges 2009; Pócs et al. 2014).

\section{Chave de identificação das espécies de Cololejeunea das áreas de canga da Serra dos Carajás}

1. Filídios com borda de células hialinas, na porção distal. Ramos do tipo-Lejeunea (com colar) 4.1. Cololejeunea cardiocarpa

1'. Filídios sem borda de células hialinas. Ramos do tipo-Aphanolejeunea (sem colar) 4.2. Cololejeunea contractiloba

4.1. Cololejeunea cardiocarpa (Mont.) A.Evans, Mem. Torrey Bot. Club 8(2): 172, 1902.

Lejeunea cardiocarpa Mont., Hist. Phys. Cuba, Bot., Pl. Cell.: 476, $1842 . \quad$ Fig. 4c-e

Planta verde-pálido a verde-amarelada, 1-1,5 mm de largura, ramos tipo-Lejeunea. Merófito ventral com 1 célula de largura. Filídios amplamente estendidos, contíguos a subimbricados, oblongo-ovalados, 500-800 × 350-650 $\mu \mathrm{m}$, ápice redondo, plano, margem inteira da base até a porção mediana, crenulada na porção distal devido a 1 camada de células hialinas, alongadas. Células medianas subisodiamétricas, 20-25 $\mu \mathrm{m}$, superfície dorsal lisa. Lóbulos oblongos, 1/3-1/4 do comprimento do lobo, dente proximal longo, com 2-3 células de comprimento, dente distal curto, 1 célula de comprimento. Perianto obovado, 5 quilhas. Reprodução vegetativa por meio de gemas arredondadas na superfície do filídio.

Material selecionado: Canaã dos Carajás, Serra Sul, S11B, 6²1'19,1'’S, 50²3'27,4”'W, 29.IV.2015, A.L. Ilkiu-Borges et al. 3516 (MG). Parauapebas, Serra Norte, $\mathrm{N} 2,6^{\circ} 03$ '28'"S, 50 ${ }^{\circ} 15^{\prime} 09^{\prime}$ 'W, $685 \mathrm{~m}, 31$.VIII.2015, A.L. Ilkiu-Borges et al. 3605 (MG); N3, 06 02'36, '”'S, $50^{\circ} 12^{\prime} 30^{\prime \prime} \mathrm{W}, 693$ m, 13.V.2017; F.R. Oliveira-da-Silva et al. 178 (MG).

Essa espécie é facilmente reconhecida pela borda de células hialinas na porção distal dos filídios oblongo-ovalados e planos, ficando bem aderidos ao substrato. Ocorre sobre folhas, galhos finos e rochas (Gradstein \& Costa 2003; Gradstein \& IlkiuBorges 2009). Nas cangas da Serra dos Carajás, Cololejeunea cardiocarpa ocorreu sobre tronco vivo e sobre folhas, sempre em mata baixa sobre canga.

Pantropical. No Brasil: AM, BA, ES, GO, MG, MS, MT, PA, PB, PE, RJ, RO, RR, SC, SE e SP. Serra dos Carajás: Serra Norte: N2 e N3; Serra Sul: S11B.
4.2. Cololejeunea contractiloba A.Evans, Amer. J. Bot. 5(3): 131, $1918 . \quad$ Fig. 4f-j

Planta verde-pálido a verde-amarelada, 0,2-0,4 mm de largura, ramos tipo-Aphanolejeunea. Merófito ventral com 1 célula de largura. Filídios obliquamente estendidos, distantes, ovalados, (lobulados) ou oblongo a oblongo-ovalados (elobulados), 100-200 × 90-120 $\mu \mathrm{m}$, ápice agudo a subagudo, plano, margem crenada a denticulada. Células medianas subisodiamétricas, 12-20 $\mu \mathrm{m}$, superfície dorsal mamilo-papilosa, célula conicamente elevada com uma papila no ápice. Lóbulos sub-ovalados, $1 / 2$ do comprimento do lobo, dente proximal e distal curtos, com 1 célula de comprimento. Perianto obovado, 5 quilhas. Reprodução vegetativa por meio de gemas arredondadas na superfície do filídio.

Material selecionado: Canaã dos Carajás, Serra Sul, S11B, 6²1'19,1'"S, 50²3'27,4”'W, 29.IV.2015, A.L. Ilkiu-Borges et al. 3518 (MG).

O pequeno porte e os filídios com células conicamente elevadas e coroadas por uma papila, conferindo aspecto áspero, são características marcantes dessa espécie. Esta espécie foi reportada pela primeira vez no Brasil em floresta de várzea sobre tronco vivo por Ilkiu-Borges \& Lisboa (2004a). Nas cangas da Serra dos Carajás, essa espécie ocorreu em mata baixa, sobre tronco vivo e folha.

Brasil, Flórida e Guiana Francesa. No Brasil: AM e PA. Serra dos Carajás: Serra Sul: S11B.

\section{Drepanolejeunea (Spruce) Steph.}

Gênero pantropical com 133 espécies, que está representado por 19 espécies no Brasil (Costa \& Peralta 2015; Söderström et al. 2016). As suas espécies ocorrem sobre folhas, galhos finos, casca 
de árvores e rochas (Gradstein et al. 2001). O gênero é reconhecido pelas plantas diminutas, com filídios assimétricos, ovalado-lanceolados com ápice agudo-acuminado (raramente redondo), presença de ocelos, anfigastros bífidos com lobos amplamente divergentes, dente do lóbulo longo e falcado (Gradstein et al. 2001; Gradstein \& Costa 2003; Gradstein \& Ilkiu-Borges 2009).

5.1. Drepanolejeunea fragilis Bischl. ex L.Söderstr., A.Hagborg \& von Konrat, Phytotaxa 65: 47, 2012.

Drepanolejeunea fragilis Bischl., Rev. Bryol. Lichénol. 33(1/2): 123, 1964 (nom. inval., fide Söderström, Hagborg \& von Konrat 2012).

Fig. 5a-e

Plantas verde-amareladas a amarronzadas com 0,2-0,6 mm de largura. Merófito ventral de 2 células. Filídios suberetos a obliquamente estendidos, falcado-lanceolados, 200-300 × 90-120 $\mu \mathrm{m}$, ápice longo-acuminado, curvado, margem irregularmente crenulada a denticulada, às vezes \pm inteira. Células sub-retangulares, 12-20 $\times$ 10-14 $\mu \mathrm{m}$. Ocelos 1-2 formando uma linha interrompida, o primeiro na linha de inserção do lobo e o segundo distanciado por 2 células comuns do primeiro, às vezes ausente. Lóbulos ovalados, 1/2 do comprimento do lobo, dente longo, dente pré-apical distinto (na junção com o lobo), geralmente quase tocando o dente apical, papila hialina proximal. Anfigastros bífidos, 1,5-2× a largura do caulídio, lobos filiformes, 2-3 células de comprimento, obliquamente divergentes.

Material selecionado: Canaã dos Carajás, Serra Sul, S11C, 6²2'57,9'S, 50²3'07'W, 29.IV.2015, A.L. Ilkiu-Borges et al. 3476 (MG). Parauapebas, Serra Norte, N2, 603'19,4'S, 50¹5'17,7''W, 685 m, 31.VIII.2015, A.L. Ilkiu-Borges et al. 3610 (MG); N3, 0602'36,1”S, 50¹2'30'W, 693 m, 13.V.2017; F.R. Oliveira-da-Silva et al. 159 (MG); N4, 604'18”S, 50¹1'39,2”W, 617 m, 3.IX.2015, A.L. Ilkiu-Borges et al. 3709 (MG); N5, 6॰02'36,4”S, 50॰05'25,1”W, 604 m, 2.IX.2015, A.L. Ilkiu-Borges et al. 3697 (MG).

Uma característica marcante desta espécie é a presença de 1 ocelo localizado na base do filídio (na linha de inserção), diferenciando-a de outras espécies de Drepanolejeunea (Bischler 1964). É facilmente reconhecida dentre as espécies das cangas de Carajás, pelas plantas diminutas com filídios lanceolados, suberetos, projetados do substrato.

Segundo Gradstein \& Costa (2003), essa espécie ocorre em casca de árvores e folhas nas florestas tropicais. Nas cangas da Serra dos Carajás, foi coletada somente sobre tronco de árvore viva perto de córrego de drenagem natural, mata baixa sobre canga e perto de campos brejosos.

América tropical. No Brasil: AM, PA, PE, ES, SP. Serra dos Carajás: Serra Norte: N2, N3, N4 e N5; Serra Sul: S11C.

\section{Harpalejeunea (Spruce) Schiffn.}

É um gênero pantropical com 32 espécies, mas apenas cinco espécies ocorrem no Brasil (Gradstein \& Costa 2003; Söderström et al. 2016). Os membros deste grupo ocorrem em troncos de árvores vivas ou troncos em decomposição e sobre folhas (Gradstein et al. 2001). O gênero caracterizase por apresentar anfigastros emarginados a curtobífidos (raramente inteiros) com lobos largos e obtusos, filídios com ápice agudo-acuminado a longo pilífero (raramente obtuso), lóbulo fortemente inflado com um dente afiado e falcado, presença de 1-3 ocelos basais ou supra-basais nos filídios e inovação lejeunóide (Gradstein et al. 2001; Gradstein \& Ilkiu-Borges 2009).

6.1. Harpalejeunea stricta (Lindenb. \& Gottsche) Steph., Sp. Hepat. 5: 259, 1913.

Lejeunea stricta Lindenb. et Gottsche, Syn. Hepat. 5: $756,1847$.

Fig. $5 f-h$

Plantas verde-acastanhadas, 0,4-0,6 mm de largura. Merófito ventral de 2 células. Filídios obliquamente estendidos, ovalado-falcados, assimétricos, 200-300 × 90-120 $\mu \mathrm{m}$, ápice curtoacuminado, terminando em uma fileira de (1-)2-3 células, incurvado, margem \pm inteira. Células medianas sub-isodiamétricas, 20-25 $\mu \mathrm{m}$, superfície lisa. Ocelos 2-3 em uma fila initerrupta na base do filídio. Lóbulos inflados, ovalados, $\pm 1 / 2$ do comprimento do lobo, dente curto, falcado, dente pré-apical curto na junção do lobo, papila hialina proximal. Anfigastros curto-bífidos, ovalados, até $1,5 \times$ a largura do caulídio, lobos amplamente arredondados.

Material selecionado: Canaã dos Carajás, Serra Norte, Serra do Tarzan, 6¹9'45'S, 5000'27,4'W, 758 m, 1.IX.2015, A.L. Ilkiu-Borges et al. 3654 (MG).

Hapalejeunea stricta é caracterizada pelos filídios ovalado-falcados com ápice curtoacuminado, terminando em uma fileira de no máximo três células e até 3 ocelos basais organizados em uma fileira initerrupta.

Ilkiu-Borges \& Lisboa (2004b) registraram H. stricta pela primeira vez no estado do Pará, em Caxiuanã, tanto em ambiente exposto (vegetação savanóide) quanto em ambiente mais úmido e sombreado (várzea), sobre tronco vivo. Nas Cangas 


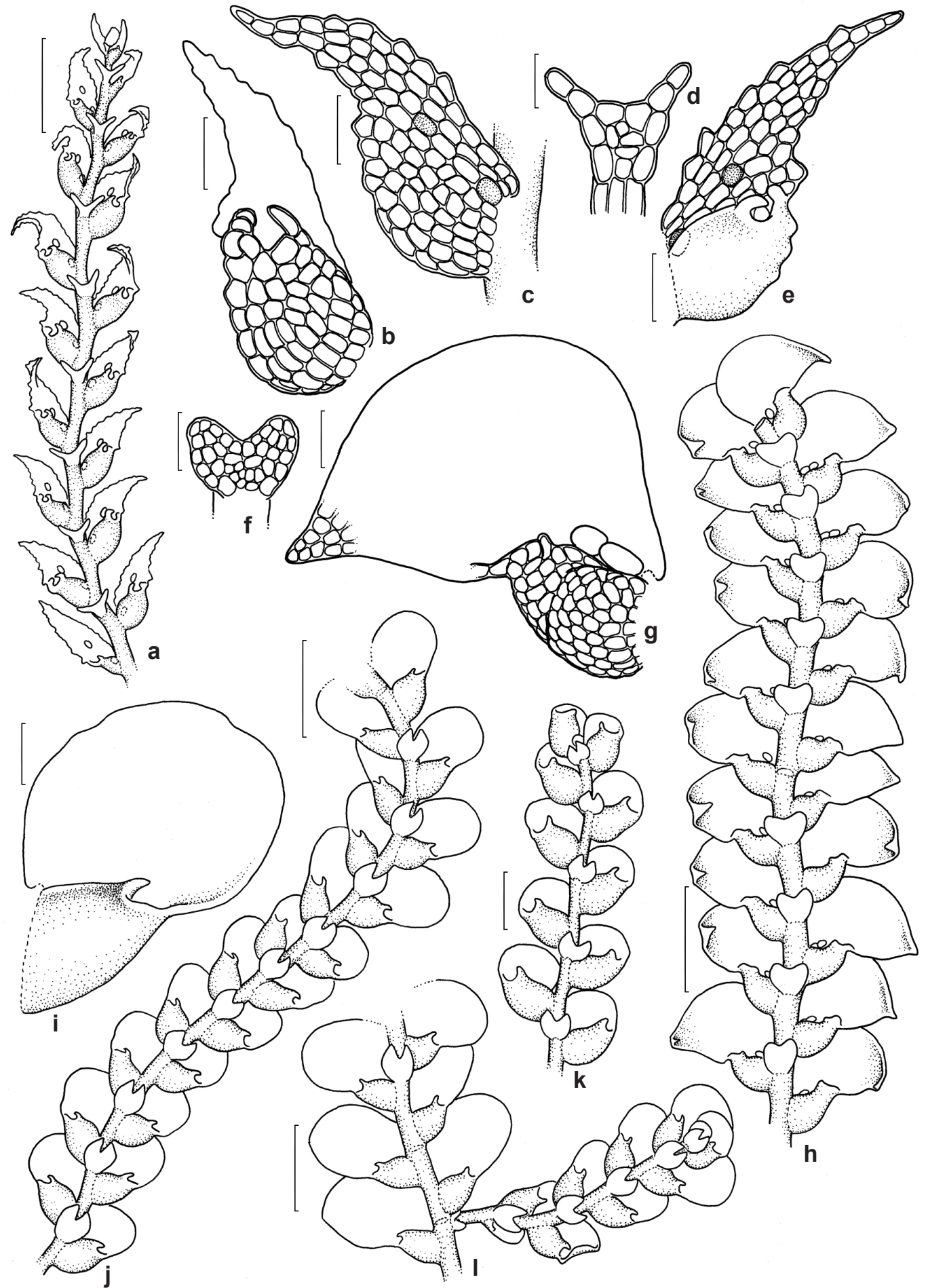

Figura 5 - a-e. Drepanolejeunea fragilis - a. hábito; b,e. filídio em vista ventral; c. filídio em vista dorsal; d. anfigastro. f-h. Harpalejeunea stricta - f. anfigastro; g. filídio em vista ventral; h. hábito. i-1. Lejeunea angusta - i. filídio em vista ventral; j,k,l. hábito. Barras: $\mathrm{a}=500 \mu \mathrm{m}$; b, c, e, f, g, i=50 $\mu \mathrm{m} ; \mathrm{d}=25 \mu \mathrm{m} ; \mathrm{h}, \mathrm{j}, \mathrm{l}=250 \mu \mathrm{m} ; \mathrm{k}=100 \mu \mathrm{m}$. ( $\mathrm{a}-\mathrm{d}$, f-h. baseado em Gradstein \& Ilkiu-Borges 2009).

Figure 5 - a-e. Drepanolejeunea fragilis - a. habit; b,e. leaf in ventral view; c. leaf in dorsal view; d. underleaf. f-h. Harpalejeunea stricta - f. underleaf; g. leaf in ventral view; h. habit. i-1. Lejeunea angusta - i. leaf in ventral view; j, k; 1. habit. Bars: a=500 $\mu \mathrm{m} ; \mathrm{b}, \mathrm{c}$, e, f, g, i=50 $\mu \mathrm{m} ; \mathrm{d}=25 \mu \mathrm{m} ; \mathrm{h}, \mathrm{j}, \mathrm{l}=250 \mu \mathrm{m} ; \mathrm{k}=100 \mu \mathrm{m}$. (a-d, f-h. after Gradstein \& Ilkiu-Borges 2009). 
da Serra dos Carajás, essa espécie ocorreu em mata baixa sobre tronco vivo.

América tropical. No Brasil: AL, BA, ES, MG, PA, PE, RJ e SP. Serra dos Carajás: Serra Sul: Serra do Tarzan.

\section{Lejeunea Libert}

É um dos maiores gêneros de Lejeuneaceae com 402 espécies distribuídas no globo, das quais 40 ocorrem no Brasil (Costa \& Peralta 2015; Söderström et al. 2016). Entretanto, muitos nomes permanecem não revisados, o que pode influenciar no número de espécies. Os membros deste grupo habitam principalmente áreas tropicais e subtropicais e ocorrem sobre troncos de árvores, folhas e rochas (ReinerDrehwald 2000; Gradstein et al. 2001). As principais características são 1) anfigastros bífidos a ocasionalmente inteiros com lobos eretos (não divergentes); 2) caulídios geralmente com hialoderme e merófito ventral com $2(-8)$ células de largura; 3 ) lóbulos ocupando ca. $1 / 2$ do comprimento do lobo, geralmente reduzidos, com papilla hialina proximal; 4) paredes celulares sem pigmentação amarronzada e oleocorpos pequenos; 5) ocelos ausentes; 6) ginoécio com inovação do tipo-lejeuneóide (Reiner-Drehwald 2000, 2005).

\section{Chave de identificação das espécies de Lejeunea das áreas de canga da Serra dos Carajás}

1. Plantas verde-pálidas, 0,6-1,2 $\mathrm{mm}$ de largura. Anfigastros ovalados a amplamente ovalados, 3-4× a largura do caulídio Lejeunea flava

1'. Plantas verde-pálidas, $0,2-0,8 \mathrm{~mm}$ de largura. Anfigastros sub-orbiculares, 1,5-2× a largura do caulídio Lejeunea angusta

2. Filídios caducos ausentes Lejeunea oligoclada

2'. Filídios caducos presentes

............
7.1. Lejeunea angusta (Lehm. \& Lindenb.) Mont., Histoire Physique, Politique et Naturelle de l'Île de Cuba, Botanique, Plantes Cellulaire 469. 1842. Jungermannia angusta Lehm. \& Lindenb., Novarum et minus cognitarum stirpium pugillus 4: 52.1832.

Fig. 5i-1

Plantas verde-pálidas, $0,2-0,7 \mathrm{~mm}$ de largura, ramos abundantes, menores que o ramo principal. Merófito ventral com 2 células de largura. Filídios obliquamente estendidos a sub-eretos, distantes a sub-imbricados, ovalados, 100-350 × 100-280 $\mu \mathrm{m}$, ápice arredondado, plano, margem inteira. Células medianas isodiamétricas, $15-20 \mu \mathrm{m}$, superfície lisa (cutícula papilosa). Lóbulos ovalados, 1/2-2/3 do comprimento do lobo, dente apical longo, falcado, papila hialina proximal. Anfigastros $\pm 1 / 3$ bífidos, sub-orbiculares, $1,5-2 \times$ a largura do caulídio, base arredondada a cuneada, lobos agudos a curto-acuminados, margem inteira. Perianto não observado. Reprodução vegetativa não observada. Material selecionado: Canaã dos Carajás, Serra Sul, Serra do Tarzan, $6^{\circ} 19^{\prime} 45^{\prime \prime} \mathrm{S}, 50^{\circ} 00^{\prime} 27,4$ ' W, $758 \mathrm{~m}$, 1.IX.2015, A.L. Ilkiu-Borges et al. 3656 (MG).

Espécie caracterizada pelas plantas relativamente pequenas, com ramos abundantes que são menores que o ramo principal, filídios com lóbulos grandes, atingindo até $2 / 3$ do comprimento do lobo, dente do lóbulo longo (20-35 $\mu \mathrm{m})$, cutícula papilosa e anfigastros pequenos, mas distintos (Reiner-Drehwald, comunicação pessoal). Essa espécie é morfologicamente similar a Lejeunea laetevirens, mas L. angusta é autoica, os lóbulos são menores (2/3 do comprimento do lobo) e os anfigastros são mais largos que longos, enquanto L. laetevirens é dioica, tem lóbulos maiores ( $2 / 5$ do comprimento do lobo) e anfigastros mais longos que largos.

Neotropical. No Brasil: BA, MG e SP. Serra dos Carajás: Serra Sul: Serra do Tarzan.

7.2. Lejeunea flava (Sw.) Nees, Naturgesch. Eur. Leberm. 3: 277, 1838.

Jungermannia flava Sw., Prodr. (Swartz): 144, 1788.

Fig. 6a-d

Plantas verde-pálidas, $0,6-1,2 \mathrm{~mm}$ de largura. Merófito ventral com 2 células de largura. Filídios obliquamente estendidos, contíguos a sub-imbricados, ovalados, 300-600 × 250-400 $\mu \mathrm{m}$, ápice obtuso a arredondado, plano, margem inteira. Células medianas isodiamétricas, 20-25 $\mu \mathrm{m}$, superfície lisa (cutícula finamente papilosa). Lóbulos ovalados, 1/3-1/4 do comprimento do lobo, dente apical curto, falcado, papila hialina proximal. Anfigastros 1/2 bífidos, ovalados a 


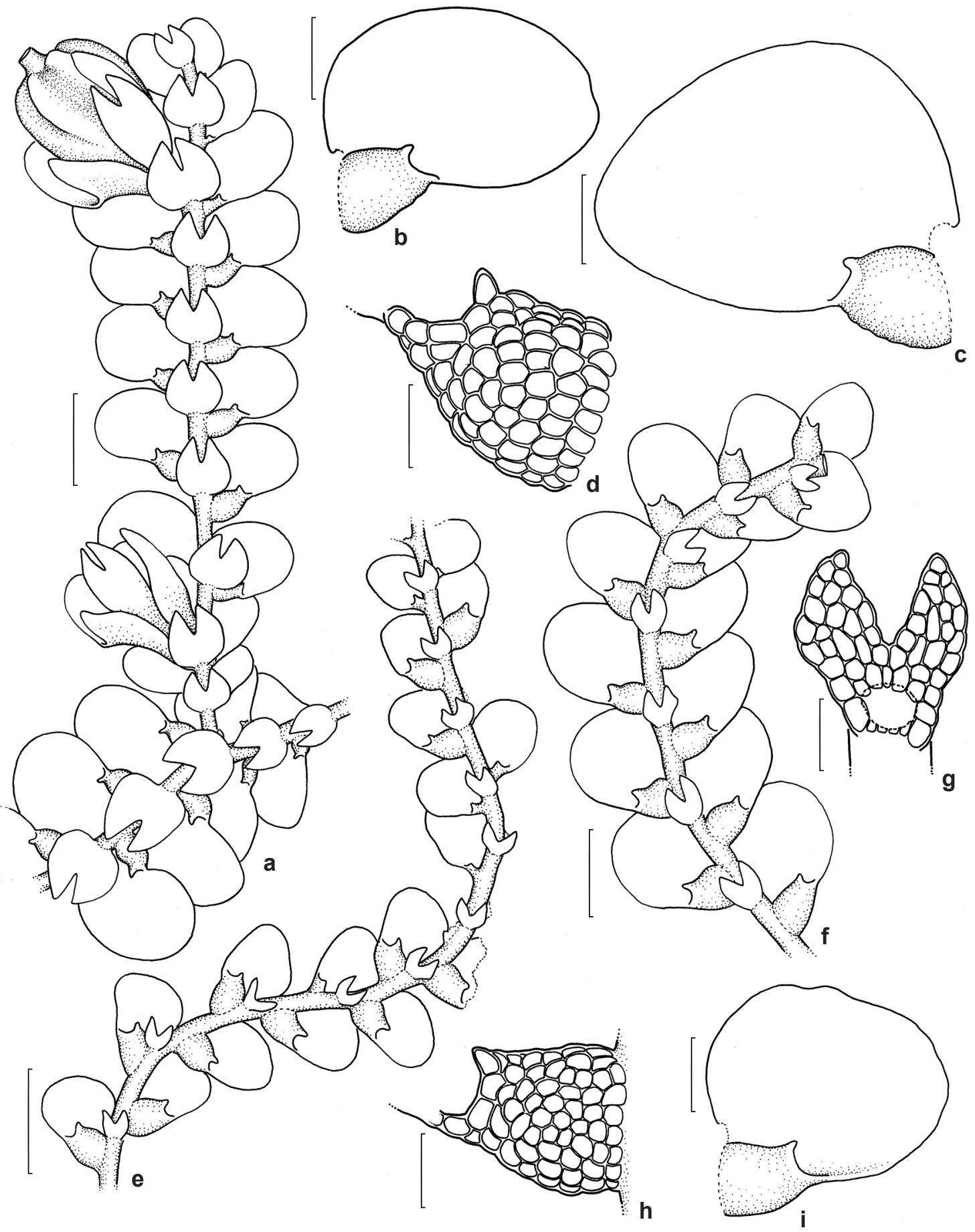

Figura 6 - a-d. Lejeunea flava - a. hábito; b,c. filídio em vista ventral; d. lóbulo. e-i. Lejeunea oligoclada - e,f. hábito; g. anfigastro; h. lóbulo; i. filídio em vista ventral. Barras: a, e, f=250 $\mu \mathrm{m} ; \mathrm{b}, \mathrm{c}, \mathrm{i}=100 \mu \mathrm{m}, \mathrm{d}, \mathrm{g}, \mathrm{h}=50 \mu \mathrm{m}$. Figure 6 - a-d. Lejeunea flava - a. habit; b,c. leaf in ventral view; d. lobule. e-i. Lejeunea oligoclada - e,f. habit; g. underleaf; h. lobule; i. leaf in ventral view. Bars: a, e, $\mathrm{f}=250 \mu \mathrm{m} ; \mathrm{b}, \mathrm{c}, \mathrm{i}=100 \mu \mathrm{m}, \mathrm{d}, \mathrm{g}, \mathrm{h}=50 \mu \mathrm{m}$. 
amplamente ovalados, 3-4× a largura do caulídio, base arredondada a \pm cordada, lobos agudos a curto-acuminados, margem inteira. Ginoécio com 1 inovação lejeuneóide. Perianto obovado, com 5 quilhas. Reprodução vegetativa não observada. Material selecionado: Canaã dos Carajás, Serra Sul, S11A, 06²0'17,9"S, 50²6'56,8”W, $731 \mathrm{~m}$, 10.V.2017; F.R. Oliveira-da-Silva et al. 52 (MG); S11B, 6²1'19,1"S, 50²3'27,4”'W, 29.IV.2015, A.L. Ilkiu-Borges et al. 3515 (MG); S11C, 6²2'57,9'S, 50²3'07'W, 29.IV.2015, A.L. Ilkiu-Borges et al. 3479 (MG); Serra do Tarzan, 6¹9'45'S, 5000'27,4”W, 758 m, 1.IX.2015, A.L. Ilkiu-Borges et al. 3656 (MG). Parauapebas, Serra Norte, N2, 603'28'S, 50¹5'09'W, 685 m, 31.VIII.2015, A.L. Ilkiu-Borges et al. 3599 (MG); N3, 0602'36, 1"S, 50¹2'30"W, 693 m, 13.V.2017; F.R. Oliveira-da-Silva et al. 149 (MG); N4, 604'18''S, 50॰11'39,2'W, 617 m, 3.IX.2015, A.L. Ilkiu-Borges et al. 3711 (MG); N5, 602'36,4”S, 5005'25,1”W, 604 m, 2.IX.2015, A.L. Ilkiu-Borges et al. 3696 (MG); N6, 66'42"S, 50¹1'01,9"'W, 711 m, 24.II.2016, A.L. IlkiuBorges et al. 3757 (MG); N7, 69'27,2”S, 50¹0'15,2'W, 695 m, 24.II.2016, A.L. Ilkiu-Borges et al. 3796 (MG).

Segundo Gradstein \& Costa (2003), esta espécie é muito comum e ocorre principalmente em tronco de árvores e rochas, e diferencia-se das demais espécies de Lejeunea pelos anfigastros largos e imbricados, cutícula finamente papilosa e quase sempre está fértil. Nas amostras das cangas da Serra dos Carajás, esta espécie encontrava-se quase sempre fértil e ocorreu sobre rocha, troncos de árvores vivas e em decomposição, em canga aberta, próximo de brejos, cavernas, córregos temporários de drenagem e em mata baixa sobre canga.

Pantropical. No Brasil: AC, AL, AM, BA, CE, DF, ES, GO, MA, MG, MS, MT, PA, PB, PE, PR, RJ, RO, RS, SC, SE, SP e TO. Serra dos Carajás: Serra Norte: N2, N3, N4, N5, N6 e N7; Serra Sul: S11A, S11B, S11C e Serra do Tarzan.

7.3. Lejeunea oligoclada Spruce, Bull. Soc. Bot. France (Congr. Bot.) 36: cxcix, 1889 [1890].

Fig. 6e-i

Plantas verde-pálidas, 0,3-0,8 $\mathrm{mm}$ de largura. Merófito ventral com 2 células de largura. Filídios obliquamente estendidos a estendidos, contíguos a sub-imbricados, ovalados, 300-400 × 250-320 $\mu \mathrm{m}$, ápice arredondado a obtuso, plano a incurvado, margem inteira. Células medianas isodiamétricas, 15-25 $\mu \mathrm{m}$, superfície lisa (cutícula finamente papilosa). Lóbulos ovalados, 1/2-1/3 do comprimento do lobo, dente apical longo, \pm falcado, papila hialina proximal. Anfigastros $\pm 1 / 2$ bífidos, sub-orbiculares, 1,5-2× a largura do caulídio, base cuneada, lobos agudos, margem inteira. Perianto não observado. Reprodução vegetativa por filídios caducos.

Material selecionado: Canaã dos Carajás, Serra Sul, Serra do Tarzan, 6¹9'49'S, 5007'53,8'W, 747 m, 1.VIII.2015, A.L. Ilkiu-Borges et al. 3678 (MG); S11C, 6²2'58,2”S, 50²3'08,3'W, 29.IV.2015, A.L. IlkiuBorges et al. 3491 (MG). Parauapebas, Serra Norte, N2, 603'19,4”'S, 50¹5'17,7’'W, 685 m, 31.VIII.2015, A.L. Ilkiu-Borges et al. 3612 (MG).

Essa espécie ocorre em tronco vivo e sobre folha, e pode ser confundida com Lejeunea phyllobola, devido aos filídios caducos, entretanto, o tamanho menor da planta e a cutícula finamente papilosa de L. oligoclada separa essas duas espécies. Reiner-Drehwald \& Schafer-Verwimp (2008), apontam como característica de $L$. oligoclada os filídios com ápice redondo e plano a agudo e recurvado, paredes celulares regularmente espessadas e lóbulos inflados recobrindo até a metade do lobo, com um dente longo (até $30 \mu \mathrm{m}$ de comprimento). Na Serra dos Carajás, os exemplares encontrados apresentam apenas ápice no máximo obtuso, mas com filídios caducos.

De acordo com Reiner-Drehwald \& SchaferVerwimp (2008), por ser conhecida apenas de Minas Gerais e Espírito Santo até Santa Catarina, essa espécie foi considrada endêmica da Costa Atlântica, entretanto a descoberta da mesma em Carajás, modifica esse cenário. De acordo com esses autores; L. oligoclada ocorrem desde vegetação de restinga até florestas submontanas, mas também em florestas secundárias, preferencialmente muito úmidas, sobre troncos de árvores vivas e em decomposição e raramente como epífilas. Nas Cangas da Serra dos Carajás, foi encontrada sobre tronco de árvore viva e em decomposição, em mata baixa sobre canga e próximo de córregos de drenagem natural.

Brasil. Brasil: AL, BA, ES, MG, PE, PR, RJ, SC, SP. Serra dos Carajás: Serra Norte: N2; Serra Sul: S11C e Serra do Tarzan.

\section{Lopholejeunea (Spruce) Steph.}

Existem 46 espécies distribuídas no globo, mas apenas três ocorrem no Brasil (Gradstein \& Costa 2003; Söderström et al. 2016). As espécies deste gênero ocorrem preferencialmente sobre troncos de árvore vivas e rochas e por ser xerotolerante, ocorre em restinga, vegetação savanóide, assim como na copa das árvores e a borda de florestas úmidas (Gradstein 1994). O gênero distingue-se pela coloração escura, células isodiamétricas com trigônios pequenos e radiados, oleocorpos homogêneos, lóbulo geralmente 
inflado-giboso, ginoécio sem inovação subfloral, perianto com 4-5 quilhas denteadas ou laciniadas (raramente inteiro) (Gradstein 1994).

8.1. Lopholejeunea subfusca (Nees) Schiffn., Bot. Jahrb. Syst. 23(5): 593, 1897.

Jungermannia subfusca Nees, Enum. Pl. Crypt. Javae: 36, 1830.

Fig. $7 \mathrm{a}-\mathrm{c}$

Plantas verde-escuras a enegrecidas, $0,7-1,4$ $\mathrm{mm}$ de largura. Merófito ventral com 4 células de largura. Filídios amplamente estendidos, imbricados, ovalados a ovalado-falcados, 450-750 $\times 350-550 \mu \mathrm{m}, \pm$ côncavos, ápice redondo, margem inteira. Células sub-isodiamétricas, $25-40 \mu \mathrm{m}$, trigônios coalescentes. Lóbulos fortemente inflados, ovalados, 1/3-2/5 do comprimento do lobo, margem livre fortemente incurvada, 1 dente no ápice, pequeno, arredondado (dificilmente visualizado). Anfigastros inteiros, amplamente ovalados, $3-4,5 \times$ a largura do caulídio. Perianto imerso, $4-5$ quilhas laciniadas (lacínias emergindo das bracteas).

Material selecionado: Canaã dos Carajás, Serra Sul, S11B, 6²1'19,1'"S, 50²3'27,4'W, 29.IV.2015, A.L. IlkiuBorges et al. 3523 (MG); S11C, 6²2'57,9'’, 50²3'07'”, 29.IV.2015, A.L. Ilkiu-Borges et al. 3476 (MG).

Caracterizada pelas plantas escuras, muitàs vezes enegrecidas, com filídios ovalados, às vezes falcados, com anfigastro inteiro e amplo (3-4,5 $\times$ a largura do caulídio). Quando fértil, o perianto imerso com quilhas laciniadas emergindo das bracteas femininas é uma característica diagnóstica (Gradstein \& Ilkiu-Borges 2009).

Segundo Gradstein (1994), L. subfusca é uma epífita xerotolerante e ocorre sobre casca de árvores e ocasionalmente sobre folhas, em florestas primárias, secundárias, vegetação savanóide, às vezes em jardins, comumente em ambientes de baixa altitude. Nas cangas da Serra dos Carajás, essa espécie foi coletada somente na Serra Sul, perto de córrego de drenagem natural e em mata baixa sobre canga, sobre tronco vivo e em decomposição.

Pantropical. No Brasil: AC, AL, AM, AP, BA, CE, DF, ES, GO, MG, MS, MT, PA, PB, PE, RJ, RO, RR, SC e SP. Serra dos Carajás: Serra Sul: $\mathrm{S} 11 \mathrm{C}$ e S11B.

\section{Microlejeunea (Spruce) Steph.}

Gênero pantropical com 52 espécies (muitas espécies necessitam ser revisadas) e apenas 10 ocorrem no Brasil (Costa \& Peralta 2015; Söderström et al. 2016). Os membros desse gênero ocorrem geralmente sobre casca de árvore, ramos finos e folhas, ocasionalmente sobre rochas ou solo (Gradstein et al. 2001). O gênero é caracterizado pelas plantas muito pequenas, com caulídio em zig-zag, filídios eretos com lóbulos muito grandes, cobrindo a maior parte do lobo (Gradstein et al. 2001).

9.1. Microlejeunea epiphylla Bischl., Nova Hedwigia 5(1/2): 378, 1963.

Fig. 7d-f

Plantas verde-claras a verde-esbranquiçadas, $0,2-0,3 \mathrm{~mm}$ de largura. Merófito ventral com 2 células de largura. Filídios eretos (quase paralelos ao caulídio), distantes, ovalados, 100-150 × 80-120 $\mu \mathrm{m}$, \pm planos, ápice arredondado, margem ventral fracamente incurvada, inteira a fracamente crenulada. Células isodiamétricas, $10-20 \mu \mathrm{m}$, superfície lisa. Ocelo 1 na base do filídio. Lóbulos inflados, ovalados, 2/3-3/4 do comprimento do lobo, quilha crenulada, 1 dente no ápice, distinto, fracamente falcado, papila hialina proximal. Anfigastros bífidos, sub-orbiculares, 1-1,5× a largura do caulídio, lobos filiformes, lobos (1-)2-3 células em fileira.

Material selecionado: Canaã dos Carajás, Serra Sul, S11A, 0602'27,3”S, 50¹6'13,3”'W, 712 m, 13.V.2017; F.R. Oliveira-da-Silva et al. 19 (MG); Serra do Tarzan,

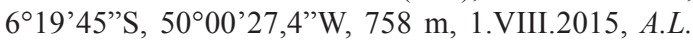
Ilkiu-Borges et al. 3664 (MG); S11C, 6²2'59,4”'S, 50²3'09,8”'W, 29.IV.2015, A.L. Ilkiu-Borges et al. 3496 (MG). Parauapebas, Serra Norte, N2, 603'20,1'S, $50^{\circ} 15^{\prime} 14,9$ 'W, 685 m, 28.IV.2015, A.L. Ilkiu-Borges et al. 3429 (MG); N3, 06 02'36, '”, 50 $0^{\circ} 12^{\prime} 30^{\prime \prime} \mathrm{W}, 693$ $\mathrm{m}, 13 . \mathrm{V} .2017$; F.R. Oliveira-da-Silva et al. 166 (MG); N7, 69'27,2”'S, 50¹0'15,2”'W, 695 m, 24.II.2016, A.L. Ilkiu-Borges et al. 3782 (MG).

Microlejeunea epiphylla é facilmente reconhecida pelas pequenas dimensões, com filídios ovalados, quase paralelos ao caulídio, e com lóbulos quase do tamanho do lobo. O ápice arredondado do filídio e a quilha crenulada por células mamilosas distinguem esta espécie de outras espécies de Microlejeunea (Bischler et al. 1963). Nas cangas da Serra dos Carajás, esta espécie ocorreu sobre tronco vivo e tronco em decomposição, em canga aberta, mata baixa, perto de lagos e de córregos de drenagem natural.

Índias Ocidentais, Guiana Francesa e Brasil. No Brasil: AL, AM, BA, CE, ES, GO, MA, MG, MS, PA, PB, PE, RJ, SE, SP e TO. Serra dos Carajás: Serra Norte: N2, N3 e N7; Serra Sul: S11A, S11C e Serra do Tarzan.

\section{Prionolejeunea (Spruce) Schiffn.}

Gênero afro-americano com 25 espécies, incluindo quatro novos táxons descritos ao longo 


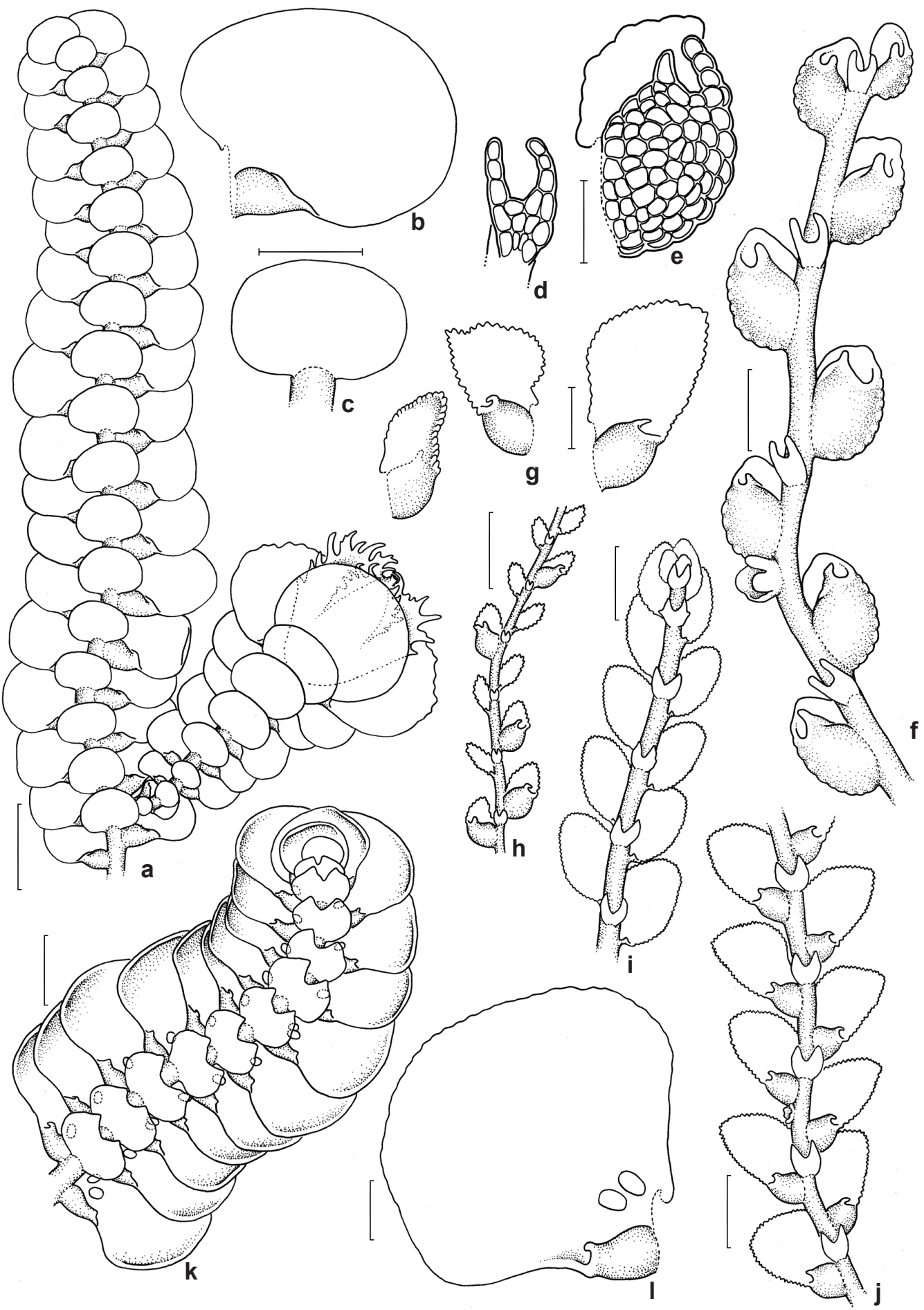

Figura 7 - a-c. Lopholejeunea subfusca - a. hábito; b. filídio em vista ventral; c. anfigastro. d-f. Microlejeunea epiphylla -d. anfigastro; e. filídio em vista ventral; f. hábito. g-j. Prionolejeunea muricatoserrulata - g. filídio; h-j. hábito. k-1. Pycnolejeunea contigua - k. hábito; 1. filídio em vista ventral. Barras: a=500 $\mu \mathrm{m}$; b, c, h, k, i, j=250 $\mu \mathrm{m}$; d, e=50 $\mu \mathrm{m}$; f, g, l=100 $\mu \mathrm{m}$. (a-f, k-1. baseado em Gradstein \& Ilkiu-Borges 2009; g-j. baseado em Ilkiu-Borges 2016).

Figure 7 - a-c. Lopholejeunea subfusca - a. habit; b. leaf in ventral view; c. underleaf. d-f. Microlejeunea epiphylla - d. underleaf; e. leaf in ventral view; f. habit. g-1. Prionolejeunea muricatoserrulata - g. leaf; h-1. habit. k-1. Pycnolejeunea contigua - k. habit; 1 . leaf in ventral view. Bars: $\mathrm{a}=500 \mu \mathrm{m} ; \mathrm{b}, \mathrm{c}, \mathrm{h}, \mathrm{k}, \mathrm{i}, \mathrm{j}=250 \mu \mathrm{m} ; \mathrm{d}, \mathrm{e}=50 \mu \mathrm{m} ; \mathrm{f}, \mathrm{g}, \mathrm{l}=100 \mu \mathrm{m}$. (a-f, k-1. after Gradstein \& Ilkiu-Borges 2009; g-j. after Ilkiu-Borges 2016). 
da revisão taxonômica e um descrito recentemente (Ilkiu-Borges \& Schafer-Verwimp 2005; Ilkiu-Borges 2016; Ilkiu-Borges et al. 2018). No Brasil, ocorrem apenas as espécies $P$. aemula (Gottsche) A.Evans, $P$. denticulata (Weber) Schiffn., P. diversitexta (Hampe \& Gottsche) Steph., P. galliotii Steph., P. limpida Herzog, P. muricatoserrulata (Spruce) Steph., P. recurvula (Spruce) Steph., P. scaberula (Spruce) Steph. e P. trachyodes (Spruce) Steph. Os membros desse gênero ocorrem geralmente em locais sombreados e não perturbados, sobre troncos de árvore viva ou sobre folhas, com menos frequência sobre tronco em decomposição, rochas e raramente sobre solo (Ilkiu-Borges 2016). O gênero é caracterizado pelos filídios denticulados por células conicamente projetadas e coroadas por uma pequena papila, lóbulos com papila hialina proximal, ausencia de ocelos, periantos com duas quilhas e inovações lejeuneóides (Ilkiu-Borges 2016).

\subsection{Prionolejeunea muricatoserrulata (Spruce)} Steph., Sp. Hepat. 5: 223, 1913.

Lejeunea muricatoserrulata Spruce, Trans. \& Proc. Bot. Soc. Edinburgh 15: 155, $1884 . \quad$ Fig. 7g-j

Plantas verde-pálidas a verde-amarronzadas, $0,2-0,6 \mathrm{~mm}$ de largura. Merófito ventral com 2 células de largura. Filídios sub-eretos, distantes a contíguos, ovalados a oblongos, $100-430 \times 50-250 \mu \mathrm{m}$, ápice agudo a sub-agudo, plano, margem denticulada, revoluta, com células cônicamente projetadas e coroadas por uma pequena papila. Células medianas isodiamétricas, $10-20 \mu \mathrm{m}$, superfície lisa (exceto células da margem). Lóbulos ovalados, 1/3-1/2 do comprimento do lobo, frequentemente reduzidos, dente apical \pm longo, falcado, papila hialina proximal. Anfigastros bífidos, orbiculares a sub-orbiculares, $1-1,5 \times$ a largura do caulídio, base cuneada, lobos agudos, margem inteira a denticulada, às vezes com 1 dente nas laterais. Perianto obcordado, com 2 quilhas laterais, achatadas com margens denticuladas a laciniadas.

Material selecionado: Parauapebas, Serra Norte, N4, $6^{\circ} 07^{\prime} 05,5^{\prime}$ 'S, 50¹1'00”'W, 3.IX.2015, A.L. Ilkiu-Borges et al. $3714(\mathrm{MG})$.

Essa espécie é facilmente identificada pelo porte pequeno das plantas com filídios de margens denticuladas por células conicamente projetadas e com anfigastros pequenos com margens geralmente denticuladas e um dente de cada lado. Típica de ambientes sombreados, essa espécie foi coletada nas cangas da Serra dos Carajás apenas em floresta alta sobre canga, sobre rocha e solo.

América Central e América do Sul. No Brasil: PA. Serra dos Carajás: Serra Norte: N4.

\section{Pycnolejeunea (Spruce) Schiffn.}

Existem 21 espécies distribuídas no globo, sendo que sete espécies ocorrem no Brasil (Costa \& Peralta 2015; Söderström et al. 2016). Os membros deste grupo ocorrem sobre troncos de árvores e caracterizam-se pela presença de ocelos no lobo do filídio, plantas esbranquiçadas a acastanhadas, caulídio rígido com células de paredes grossas, lobo do filídio redondo e inteiro, trigônios grandes, oleocorpos grandes e grosseiramente granulares, anfigastros amplos e pela inovação pycnolejeunóide (Gradstein et al. 2001).

11.1. Pycnolejeunea contigua (Nees) Grolle; j. Hattori Bot. Lab. 45: 179, 1979.

Jungermannia contigua Nees, Fl. bras. (Martius) 1(1): 360, 1833.

Fig. 7k-1

Plantas verde-esbranquiçadas a verdeescuras, $0,9-1,5 \mathrm{~mm}$ de largura. Merófito ventral com 2 células de largura. Filídios amplamente estendidos, imbricados, ovalado-orbiculares, quase falcados, 300-500 × 350-500 $\mu \mathrm{m}$, ápice amplamente arredondado, incurvado, margem inteira a fracamente crenulada. Células medianas isodiamétricas, $20-30 \mu \mathrm{m}$, superfície lisa. Ocelos 1-6 suprabasais agregados. Lóbulos ovalados, 1/4-1/5 do comprimento do lobo, dente apical curto, falcado, papila hialina proximal. Anfigastros bífidos, amplamente ovalados, 3-4× a largura do caulídio, base arredondada, lobos agudos a subagudos, margem inteira. Perianto obovado, 5 quilhas achatadas, inteiras.

Material selecionado: Canaã dos Carajás, Serra Sul, S11A, 06 02'27,3"S, 50 16'13,3'W, 712 m, 13.V.2017; F.R. Oliveira-da-Silva et al. 19 (MG). Parauapebas, N1, 601'32,3”S, 50¹7'32,5”'W, 719 m, 28.IV.2015, A.L. Ilkiu-Borges et al. 3437 (MG); N2, 603'19,2”'S, 50 15'14,7'W, 685 m, 28.IV.2015, A.L. Ilkiu-Borges et al. 3436 (MG); N5, 602'36,4”'S, 5005'25,1'W, 604 $\mathrm{m}, 2 . I X .2015$, A.L. Ilkiu-Borges et al. 3696 (MG); N6, 6 6'42"'S, 50¹1'01,9'W, 711 m, 24.II.2016, A.L. IlkiuBorges et al. 3756 (MG); N7, 6ㅇ'27, 2"'S, 50¹0'15,2”'W, 695 m, 24.II.2016, A.L. Ilkiu-Borges et al. 3799 (MG).

Se distingue pelas plantas relativamente grandes, com filídios concavos, fortemente imbricados e com ocelos suprabasais. Essa espécie ocorre como epífita no dossel de florestas tropicais, crescendo em ramos finos e nas porções mais altas dos troncos de árvores, mas também pode ocorrer em vegetação savanóide, em árvores isoladas em cerrado e restinga (Gradstein \& Costa 2003). Nas cangas da Serra dos Carajás, essa espécie ocorreu sobre tronco vivo ou em decomposição e sobre rocha, próximo a campos brejosos, à margens de 
lagos, córregos de drenagem natural, em mata baixa sobre canga e canga aberta.

Pantropical. No Brasil: AM, BA, CE, ES, MG, PA, PE, RR, RS, SC e SP. Serra dos Carajás: Serra Norte: N1, N2, N5, N6 e N7; Serra Sul: S11A.

\section{Schiffneriolejeunea Verd.}

Gênero pantropical com 14 espécies (e três taxa infraespecíficos), das quais duas ocorrem no Brasil (Gradstein \& Costa 2003; Gradstein
2015; Söderström et al. 2016; Wang et al. 2017). Os membros deste gênero ocorrem sobre troncos de árvores vivas e em decomposição em ambiente preferencialmente mésicos ou em vegetação savanóide ou na borda de florestas (Gradstein 1994). O gênero é reconhecido pela coloração marrom, ausência de inovação no ginoécio, caulídio sem hialoderme, oleocorpos segmentados e perianto com duas quilhas laterais e duas ventrais infladas (Gradstein 1994).

\section{Chave de identificação das espécies de Schiffneriolejeunea das áreas de canga da Serra dos Carajás}

1. Lóbulos ovalado-retangulares, 1/2-3/5 o comprimento do lobo, com 2 dentes no ápice

12.1. Schiffneriolejeunea amazonica

1'. Lóbulos ovalados, 1/2-1/3 o comprimento do lobo, com 1 dente no ápice

12.2. Schiffneriolejeunea polycarpa

12.1. Schiffneriolejeunea amazonica Gradst., Beih. Nova Hedwigia 80: 25, $1985 . \quad$ Fig. 8a-b

Plantas verde-acastanhadas a enegrecidas quando secas, 1-1,5 $\mathrm{mm}$ de largura. Merófito ventral com 4 células de largura. Filídios suberetos a adpressos ao caulídio quando secos, obliquamente estendidos quando úmidos, imbricados, ovaladooblongos, 500-800 × 350-500 $\mu \mathrm{m}$, côncavos, ápice amplamente arredondado, incurvado, margem inteira. Células medianas elongadas, 30-40 × 20 $\mu \mathrm{m}$, trigônios cordados, superfície lisa. Lóbulos ovalado-retangulares, 1/2-3/5 o comprimento do lobo, com 2 dentes no ápice. Anfigastros inteiros, amplamente obovados, $\pm 4 \times$ a largura do caulídio, base arredondada, ápice arredondado, margem inteira. Perianto imerso, longo-obovado, 4 quilhas (2 laterais e 2 ventrais), infladas, lisas.

Material selecionado: Parauapebas, Serra Norte, N5, 602'36,4”S, 5005’25,1"W, 604 m, 2.IX.2015, A.L. Ilkiu-Borges et al. 3696 (MG).

Distingue-se de Schiffneriolejeunea polycarpa (Nees) Gradst., também coletada em Carajás, principalmente pelos filídios fortemente côncavos, com lóbulos com 2 dentes no ápice (filídios \pm planos e lóbulos com 1 dente discreto no ápice em S. polycarpa). Segundo Gradstein (1994), esta espécie é epífita e ocorre sobre árvores pequenas em florestas secas, caatinga e em vegetação savanóide na Amazônia. Nas cangas da Serra dos Carajás, esta espécie foi coletada próximo de um campo brejoso no período mais seco, sobre tronco vivo.

Brasil, Suriname, Peru, Bolívia e Guiana Francesa. No Brasil: AM e RO. Serra dos Carajás: Serra Norte: N2.
12.2. Schiffneriolejeunea polycarpa (Nees) Gradst.; j. Hattori Bot. Lab. 38: 335, 1974.

Jungermannia polycarpa Nees, Fl. bras. (Martius) 1(1): 350, 1833. Fig. $8 \mathrm{c}-\mathrm{f}$

Plantas verde a verde-escuras vivas, acastanhadas a marrons quando secas, $1,5-2 \mathrm{~mm}$ de largura. Merófito ventral com 5-8 células de largura. Filídios suberetos e convolutos quando secos, estendidos e convexos quando úmidos, imbricados, ovalado-orbiculares, 700-1000 $\times$ 500-800 $\mu \mathrm{m}$, ápice amplamente arredondado, \pm plano, margem inteira. Células medianas elongadas, $20-30 \times 14-20 \mu \mathrm{m}$, trigônios cordados, superfície lisa. Lóbulos ovalados, $1 / 2-1 / 3$ o comprimento do lobo, com 1 dente no ápice. Anfigastros inteiros, amplamente obovados, $\pm 4 \times$ a largura do caulídio, base arredondada, ápice truncado, às vezes revoluto, margem inteira. Perianto imerso (ou emergente até $1 / 3$ ), longoobovado, 4-5 quilhas (2 laterais, 1-2 ventrais, 1 dorsal), infladas, lisas.

Material selecionado: Canaã dos Carajás, S11C, 622'57,9'S, 50²3'07'W, 29.IV.2015, A.L. IlkiuBorges et al. 3473 (MG); Serra do Tarzan, $6^{\circ} 19^{\prime} 49,8^{\prime \prime} \mathrm{S}$, $50^{\circ} 07{ }^{\prime} 55,1$ 'W, 742 m, 1.IX.2015, A.L. Ilkiu-Borges et al. 3674 (MG). Parauapebas, N1, 601'34,1'S, 50¹7'31,8”W, 719 m, 28.IV.2015, A.L. Ilkiu-Borges et al. 3450 (MG); N2, 603'28'"S, 50 ${ }^{\circ} 15^{\prime} 09^{\prime \prime} \mathrm{W}, 685 \mathrm{~m}$, 31.VIII.2015, A.L. Ilkiu-Borges et al. 3602 (MG); N4, 6004'18"'S, 50¹1'39,2'W, 617 m, 3.IX.2015, A.L. IlkiuBorges et al. 3702 (MG); N7, 69'27,2”S, 50'10'15,2”W, 695 m, 24.II.2016, A.L. Ilkiu-Borges et al. 3789 (MG).

As diferenças entre $S$. polycarpa e $S$. amazonica são discutidas sob essa última espécie. De acordo com Gradstein (1994), S. polycarpa 
tem uma distribuição disjunta, sendo comum nas porções norte e sudeste do Neotrópico, mas está ausente ou é muito rara nas porções úmidas do Neotrópico equatorial. Segundo esse mesmo autor essa é uma espécie xerotolerante que cresce como corticícola ou epíxila em florestas perturbadas, vegetação savanóide, à margem de rodovias e em plantações. Nas cangas da Serra dos Carajás, esta espécie foi coletada em tronco de árvore viva e uma vez sobre rocha de ferro, em mata baixa sobre canga, canga aberta, próximo de córregos de drenagem natural e de lagos.

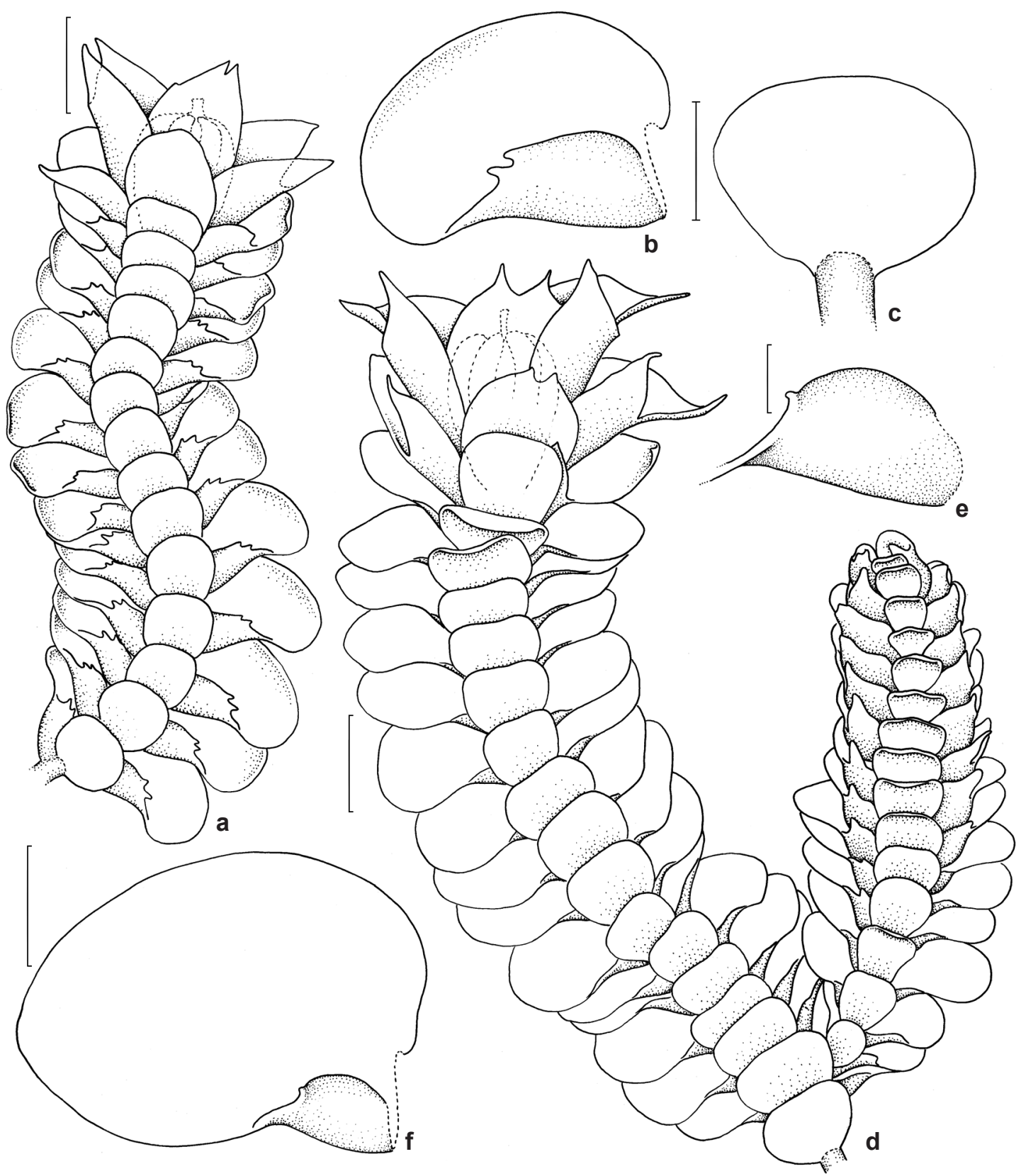

Figura 8 - a-b. Schiffneriolejeunea amazonica - a. hábito; b. filídio em vista ventral. c-f. Schiffneriolejeunea polycarpa - c. anfigastro; d. hábito; e. lóbulo; f. filídio em vista ventral. Barras: a, d=500 $\mu \mathrm{m} ; \mathrm{b}, \mathrm{c}, \mathrm{f}=250 \mu \mathrm{m}, \mathrm{e}=100$ $\mu \mathrm{m}$. (a-b. baseado em Gradstein \& Ilkiu-Borges 2009).

Figure 8 - a-b. Schiffneriolejeunea amazonica - a. habit; b. leaf in ventral view. c-f. Schiffneriolejeunea polycarpa - c. underleaf; d. habit; e. lobule; f. leaf in ventral view. Bars: a, $d=500 \mu \mathrm{m} ; \mathrm{b}, \mathrm{c}, \mathrm{f}=, 250 \mu \mathrm{m}, \mathrm{e}=100 \mu \mathrm{m}$. (a-b. after Gradstein \& Ilkiu-Borges 2009). 
América tropical, África, Índia, Sri Lanka, Tailândia e China. No Brasil: AC, AL, AM, BA, CE, DF, ES, GO, MG, MS, MT, PA, PB, PE, RJ, RO, RS, SC, SE e SP. Serra dos Carajás: Serra Norte: N1, N2, N4 e N7; Serra Sul: S11C e Serra do Tarzan.

\section{Agradecimentos}

Agradecemos à Dra. Maria Elena ReinerDrehwald, o auxílio na identificação de Lejeunea angusta; ao Museu Paraense Emílio Goeldi e Instituto Tecnológico Vale, a infraestrutura e demais apoios fundamentais para o desenvolvimento deste trabalho, assim como à Dra. Ana Maria Giulietti Harley e ao Dr. Pedro Viana, coordenadores do projeto conveniado MPEG/ITV/FADESP (01205.000250/2014-10) e ao projeto aprovado pelo CNPq (processo 455505/2014-4), o financiamento; ao ICMBio, em especial ao biólogo Frederico Drumond Martins, a licença de coleta concedida e suporte nos trabalhos de campo; ao $\mathrm{CNPq}$, a bolsa de Mestrado concedida ao segundo autor e a bolsa de Produtividade em Pesquisa concedida à primeira autora.

\section{Referências}

Bastos CJP \& Yano O (2009) O gênero Lejeunea Libert (Lejeuneaceae) no estado da Bahia, Brasil. Hoehnea 36: 303-320.

Bastos CJP (2016) Notas taxonômicas sobre espécies do gênero Cheilolejeunea (Spruce) Steph. (Lejeuneaceae, Marchantiophyta) descritas por R.M. Schuster para a Jamaica e Venezuela. Hoehnea 43: 635-643.

Bastos CJP (2017) O gênero Cheilolejeunea (Spruce) Steph. (Lejeuneaceae, Marchantiophyta) nas Américas. Pesquisas, Botânica 70: 05-78.

Bischler H (1964) Le genre Drepanolejeunea Steph. En Amérique Centrale et Méridionale. Revue Bryologique et Lichénologique 33: 15-179.

Bischler H, Bonner CEB \& Miller HA (1963) Studies in Lejeuneaceae VI. The genus Microlejeunea Steph. in Central and South America. Nova Hedwigia 5: 359-423.

Brito ES \& Ilkiu-Borges AL (2012) A new species of Ceratolejeunea Jack \& Steph. (Lejeuneaceae, Jungermanniopsida) from a remnant of Amazonian forest in Maranhão, Brazil. Nova Hedwigia 95: 423-428.

Costa DP \& Peralta DF (2015) Bryophytes diversity in Brazil. Rodriguésia, 66: 1063-1071.

Dauphin G (2003) Ceratolejeunea. Flora Neotropica Monograph 90: 1-86.
Gradstein SR (1994) Lejeuneaceae: Ptychanteae, Brachiolejeuneae. Flora Neotropica Monograph 62: 1-216.

Gradstein SR, Churchill SP \& Salazar-Allen N (2001) Guide to the Bryophytes of tropical America. Memoirs of the New York Botanical Garden 86: $1-577$.

Gradstein SR \& Costa DP (2003) The Hepaticae and Anthocerotae of Brazil. Memoirs of The New York Botanical Garden 87: 1-318.

Gradstein SR \& Ilkiu-Borges AL (2009) Guide to the Plants of Central French Guiana. Part 4. Liverworts and Hornworts. Memoirs of The New York Botanical Garden 76: 1-140.

Gradstein SR (2015) An overview of the genus Schiffneriolejeunea. Nova Hedwigia 100: 507-524.

Grolle R \& Reiner-Drehwald ME (1997) Cheilolejeunea oncophylla (Angstr.) Grolle \& Reiner comb. nov (Lejeuneaceae), from Neotropics. Journal of Bryology 19: 781-785.

Ilkiu-Borges AL (2016) Prionolejeunea (Lejeuneaceae, Jungermanniopsida). Flora Neotropica Monograph 116: 1-126.

Ilkiu-Borges AL \& Schafer-Verwimp A (2005) On Prionolejeunea grollei, a new species from the West Indies (Lejeuneaceae, Hepaticae). Cryptogamie, Bryologie 26: 29-35.

Ilkiu-Borges AL, Dauphin G \& Salazar-Allen N (2018) Prionolejeunea clementinae, a new species of Lejeuneaceae (Marchantiophyta) from Panama. Nova Hedwigia 106: 65-71.

Ilkiu-Borges AL \& Lisboa RCL (2004a) Cololejeuneae (Lejeuneaceae, Hepaticae) na estação Científica Ferreira Pena, Melgaço, PA, Brasil. Acta Botanica Brasilica 18: 887-902.

Ilkiu-Borges AL \& Lisboa RCL (2004b) Os gêneros Cyclolejeunea, Haplolejeunea, Harpalejeunea, Lepidolejeunea e Rectolejeunea (Lejeuneaceae, Hepaticae) na estação Científica Ferreira Pena, Pará, Brasil. Acta Botanica Brasilica 18: 537-553.

Pócs T, Bernercker A \& Tixier P (2014) Synopsis and key to species of Neotropical Cololejeunea (Lejeuneaceae). Acta Botanica Hungarica 562: 185-226.

Reiner-Drehwald ME (2000) Las Lejeuneaceae (Hepaticae) de Misiones, Argentina VI. Lejeunea y Taxilejeunea. Tropical Bryology 19:81-132.

Reiner-Drehwald ME (2005) On Amphilejeunea and Cryptogynolejeunea, two small genera of Lejeuneaceae (Jungermanniopsida), and two common neotropical Lejeunea species. Nova Hedwigia 81: 395-411.

Reiner-Drehwald ME \& Schäfer-Verwimp A (2008) Lejeunea oligoclada and L. rionegrensis (Lejeuneaceae) in tropical America: new data on morphology and geographical distribution. Nova Hedwigia 87: 175-184. 
Söderström L, Hagborg A \& von Konrat M (2012). Notes on Early Land Plants Today. 5. Validation of two Drepanolejeunea species. Phytotaxa 65: 47-48.

Söderström L, Hagborg A, von Konrat M, BartholomewBegan S, Bell D, Briscoe L, Brown E, Cargill DC, Costa DP, Crandall-Stotler BJ, Cooper ED, Dauphin G, Engel JJ, Feldberg K, Glenny D, Gradstein SR, He X- L, Heinrichs J, Hentschel J, Ilkiu-Borges AL, Katagiri T, Konstantinova NA, Larraín J, Long DG, Nebel M, Pócs M, Puche F, Reiner-Drehwald E, Renner MAM, Sass-Gyarmati A, Schäfer-Verwimp A, Moragues JGS, Stotler RE, Sukkharak P, Thiers BM, Uribe J, Váňa J, Villarreal JC, Wigginton M, Zhang L \& Zhu R-L (2016) World Checklist of hornwrts and liverworts. Phytokeys 59: 1-828.
Wang J, Gradstein SR, Shi X-Q \& Zhu R-L (2014) Phylogenetic position of Trocholejeunea and a new infrageneric classification of Acrolejeunea (Lejeuneaceae, Marchantiophyta). Bryophyte Diversity and Evolution 1: 31-44.

Wang J, Zhu R-L \& Gradstein SR (2017) Taxonomic revision of Lejeuneaceae subfamily Ptychanthoideae in China. Bryophytorum Bibliotheca 65: 1-141.

Ye W, Gradstein SR, Shaw AJ, Shaw B, Ho B-C, Schäfer-Verwimp A, Pócs T, Heinrichs J \& Zhu, R-L (2015) Phylogeny and classification of Lejeuneaceae subtribe Cheilolejeuneinae (Marchantiophyta) based on nuclear and plastid molecular markers. Cryptogamie, Bryologie 36: 313-333.

\section{Lista de exsicatas}

Ilkiu-Borges AL et al. 3629 (1.1), 3422 (1.2), 3432 (1.2), 3438 (1.2), 3440 (1.2), 3441 (1.2), 3444 (1.2), 3445 (1.2), 3447 (1.2), 3449 (1.2), 3477 (1.2), 3480 (1.2), 3484 (1.2), 3511 (1.2), 3519 (1.2), 3601 (1.2), 3641 (1.2), 3710 (1.2), 3720 (1.2), 3734 (1.2), 3736 (1.2), 3737 (1.2), 3738 (1.2), 3741 (1.2), 3759 (1.2), 3785 (1.2), 3798 (1.2), 3804 (1.2), 3806 (1.2), $3476(2.1), 3618$ (2.1), $3696(2.1), 3697$ (2.1), $3698(2.1), 3702(2.1), 3711(2.1), 3709$ (2.1), 3714 (2.1), 3525 (2.2), $3526(2.2), 3478(2.3), 3479(2.3), 3494$ (2.3), $3395(2.3)$, 3397 (2.3), 3489 (2.3), 3493 (2.3), 3503 (2.3), 3610 (2.3), 3654 (2.3), 3667 (2.3), 3612 (3.1), 3627 (3.1), 3655 (3.1), 3657 (3.1), 3658 (3.1), 3659 (3.1), 3665 (3.1), 3704 (3.1), 3706 (3.1), 3709 (3.1), 3380 (3.2), 3381 (3.2), 3395 (3.2), 3625 (3.2), 3648 (3.2), 3653 (3.2), 3654 (3.2), 3666 (3.2), 3702 (3.2), 3710 (3.2), 3716 (3.2), 3717 (3.2), 3721 (3.2), 3738 (3.2), 3633 (3.2), 3635 (3.2), 3697 (3.2), 3698 (3.2), 3397 (3.3), 3441 (3.3), 3449 (3.3), 3473 (3.3), 3484 (3.3), 3511 (3.3), 3517 (3.3), 3522 (3.3), 3525 (3.3), 3596 (3.3), 3599 (3.3), 3601 (3.3), 3602 (3.3), 3603 (3.3), 3611 (3.3), 3398 (3.3), 3429 (3.3), 3438 (3.3), 3450 (3.3), 3476 (3.3), 3489 (3.3), 3494 (3.3), 3497 (3.3), 3498 (3.3), 3502 (3.3), 3503 (3.3), 3504 (3.3), 3515 (3.3), 3623 (3.3), 3626 (3.3), 3667 (3.3), 3717 (3.3), 3721 (3.3), 3722 (3.3), 3758 (3.3), 3782 (3.3), 3429 (3.4), 3518 (3.4), 3611 (3.4), 3612 (3.4), 3613 (3.4), 3614 (3.4), $3616(3.4), 3618(3.4), 3516(4.1), 3522$ (4.1), 3605 (4.1), 3518 (4.2), 3522 (4.2), 3476 (5.1), 3494 (5.1), 3498 (5.1), 3499 (5.1), 3610 (5.1), 3612 (5.1), 3623 (5.1), 3624 (5.1), 3626 (5.1), 3697 (5.1), 3702 (5.1), 3709 (5.1), 3711 (5.1), 3654 (6.1), 3654 (7.1), 3667 (7.1), 3386 (7.2), 3393 (7.2), 3394 (7.2), 3396 (7.2), 3397 (7.2), 3473 (7.2), 3477 (7.2), 3479 (7.2), 3480 (7.2), 3482 (7.2), 3493 (7.2), 3498 (7.2), 3499 (7.2), 3504 (7.2), 3511 (7.2), 3515 (7.2), 3517 (7.2), 3519 (7.2), 3520 (7.2), 3521 (7.2), 3522 (7.2), 3523 (7.2), 3524 (7.2), 3597 (7.2), 3598 (7.2), 3599 (7.2), 3604 (7.2), 3610 (7.2), $3619(7.2), 3621$ (7.2), 3625 (7.2), 3656 (7.2), 3696 (7.2), 3702 (7.2), 3704 (7.2), 3709 (7.2), 3710 (7.2), 3711 (7.2), 3715 (7.2), 3716 (7.2), 3717 (7.2), 3721 (7.2), 3734 (7.2), 3744 (7.2), 3757 (7.2), 3761 (7.2), 3781 (7.2), 3793 (7.2), $3794(7.2), 3798$ (7.2), 3799 (7.2), 3800 (7.2), 3603 (7.2), 3678 (7.3), 3650 (7.3), 3491 (7.3), 3612 (7.3), 3476 (8.1), 3477 (8.1), 3480 (8.1), 3483 (8.1), 3494 (8.1), 3497 (8.1), 3498 (8.1), 3504 (8.1), 3523 (8.1), 3429 (9.1), 3432 (9.1), $3433(9.1), 3440(9.1), 3483(9.1), 3484(9.1), 3596$ (9.1), 3737 (9.1), 3782 (9.1), 3664 (9.1), 3714 (10.1), 3436 (11.1), 3437 (11.1), 3440 (11.1), 3444 (11.1), 3696 (11.1), 3734 (11.1), 3735 (11.1), 3737 (11.1), 3738 (11.1), 3744 (11.1), 3745 (11.1), 3756 (11.1), 3781 (11.1), 3794 (11.1), 3799 (11.1), 3696 (12.1), 3494 (12.2), 3450 (12.2), 3473 (12.2), 3476 (12.2), 3477 (12.2), 3480 (12.2), 3490 (12.2), 3491 (12.2), 3494 (12.2), 3497 (12.2), 3498 (12.2), 3504 (12.2), 3511 (12.2), 3602 (12.2), 3633 (12.2), 3638 (12.2), 3640 (12.2), 3642 (12.2), 3674 (12.2), 3702 (12.2), 3706 (12.2), 3789 (12.2). Oliveira-da-Silva FR et al. 19 (1.2), 20 (1.2), 34 (1.2), 39 (1.2), 40 (1.2), 43 (1.2), 46 (1.2), 172 (2.1), 176 (3.1), 41 (3.1), 47 (3.1), 19 (3.2), 45 (3.2), 52 (3.2), 172 (3.3), 178 (3.3), 178 (4.1), 181 (4.1), 159 (5.1), $166(5.1), 181$ (5.1), 44 (7.2), 46 (7.2), 48 (7.2), 52 (7.2), 149 (7.2), 150 (7.2), 151 (7.2), 153 (7.2), 155 (7.2), 156 (7.2), 158 (7.2), 159 (7.2), 160 (7.2), 161 (7.2), 166 (7.2), 168 (7.2), 170 (7.2), 172 (7.2), 173 (7.2), 177 (7.2), 178 (7.2), 180 (7.2), 181 (7.2), 19 (9.1), 38 (9.1), 39 (9.1), 44 (9.1), 48 (9.1), 52 (9.1), 166 (9.1), $178(9.1), 19(11.1), 40(11.1), 48(11.1)$. 